\title{
Effects and Mechanisms of Five Psoralea Prenylflavonoids on Aging-Related Diseases
}

\author{
Yi-Ting Zhou, ${ }^{1,2}$ Lin Zhu, ${ }^{1,2}$ Yunyun Yuan $\mathbb{D D}^{1}{ }^{1}$ Shuang Ling $\mathbb{D}^{1},{ }^{1}$ and Jin-Wen Xu $\mathbb{D}^{1}$ \\ ${ }^{1}$ Institute of Interdisciplinary Medical Science, Shanghai University of Traditional Chinese Medicine, Shanghai 201203, China \\ ${ }^{2}$ Clinical Medicine of Integrated Chinese and Western Medicine in Shanghai University of Traditional Chinese Medicine, \\ Shanghai 201203, China
}

Correspondence should be addressed to Shuang Ling; sarah_ling@126.com and Jin-Wen Xu; jwxu1001@163.com

Received 24 February 2020; Revised 12 May 2020; Accepted 28 May 2020; Published 18 June 2020

Academic Editor: Hassan Obied

Copyright (c) 2020 Yi-Ting Zhou et al. This is an open access article distributed under the Creative Commons Attribution License, which permits unrestricted use, distribution, and reproduction in any medium, provided the original work is properly cited.

\begin{abstract}
During the aging process, senescent cells gradually accumulate in the organs; they secrete proinflammatory cytokines and other factors, collectively known as the senescence-associated secretory phenotype (SASP). SASP secretions contribute to "inflammaging," which is a state of chronic, systemic, sterility, low-grade inflammatory microenvironment and a key risk factor in the development of aging-related diseases. Fructus psoraleae is a traditional Chinese medical herb best known for delaying aging and treating osteoporosis. Prenylflavonoids from fructus psoraleae are the main bioactive compounds responsible for its pharmacological applications, such as beaching, bavachinin, bavachalcone, isobavachalcone, and neobavaisoflavone. In previous decades, there have been some promising studies on the pharmacology of fructus psoraleae. Here, we focus on the antiinflammatory and antiaging diseases of five psoralea prenylflavonoids, such as cardiovascular protection, diabetes and obesity intervention, neuroprotection, and osteoporosis, and discuss the mechanism of these active ingredients for better understanding the material basis and drug application of fructus psoraleae in Chinese medicine.
\end{abstract}

\section{Introduction}

Fructus psoraleae (补骨脂), a traditional Chinese medical herb, is the dried and mature fruit of Psoralea corylifolia Linn., which is an annual herb of Leguminosae (Figures $1(\mathrm{a})-1(\mathrm{c})$ ). After drying, the psoraleae fruits are mixed with salt water and gently stir-baked until the fruits are slightly swollen. Then, the salt-processed fructus psoraleae could be used as a traditional Chinese medicine in the clinic. Fructus psoraleae is considered to have the efficacy of "relieving chronic morning diarrhea, warming and invigorating the Kidney-Yang, gathering the spirit, and enriching the bone marrow" in the Compendium of Materia Medica. According to the traditional Chinese medicine theories, fructus psoraleae has the function of delaying aging. The chemical constituents of fructus psoraleae mainly include coumarin, terpenoid phenols, and prenylflavonoids, which are the therapeutic material basis of fructus psoraleae. The structure of prenylflavonoids is characterized by the presence of isopentenyl side chains on the flavonoid skeletons. The structural types of isopentenyl are mainly 5 kinds of side chains: isopentenyl, hydroxyisopentenyl, pyran ring isopentenyl, lavender, and hydroxylavender. Most of psoralea prenylflavonoids are contained in ethyl acetate extract active fractions from Psoralea corylifolia $[1,2]$. A recent study has shown that all the tested compounds in Psoralea corylifolia were absorbed into the blood plasma of rats rapidly, almost evenly distributed in the brain parenchyma, and the overall trend in the brain was basically similar to the results of plasma concentration time. Moreover, in terms of the ratio of total brain to plasma, isoprene flavonoids were easier to enter the brain than coumarin [3]. Another pharmacokinetic report also showed that rats taking oral administration and intraperitoneal injection with $20 \mathrm{mg} / \mathrm{kg}$ bavachalcone were detected with maximum plasma concentrations of 165 and $740 \mu \mathrm{g} / \mathrm{L}$, with a drug half-life of 1 and $1.25 \mathrm{~h}$, respectively [4]. Fructus psoraleae has certain hepatotoxicity mainly caused by its constituents, such as bakuchiol, psoralen, and isopsoralen $[5,6]$. Some psoralea 


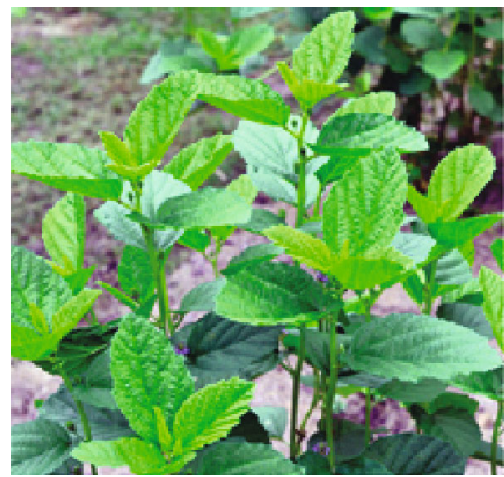

(a)

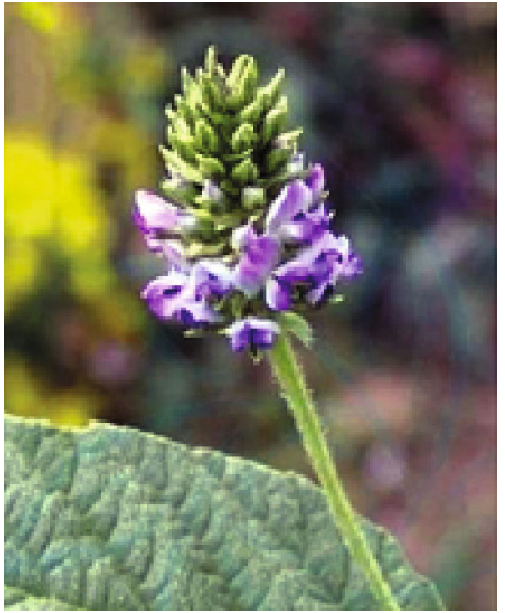

(b)<smiles>CC(C)=CCc1cc2c(cc1O)O[C@H](c1ccc(O)cc1)CC2=O</smiles><smiles>COc1cc2c(cc1CC=C(C)C)C(=O)C[C@@H](c1ccc(O)cc1)O2</smiles>

Bavachalcone

Isabavachalcone

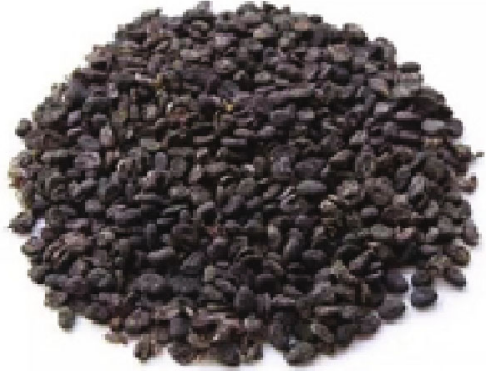

(c)<smiles>CC(C)=CCc1cc(C(=O)/C=C/c2ccc(O)cc2)c(O)cc1O</smiles><smiles>CC(C)=CCc1c(O)ccc(C(=O)/C=C/c2ccc(O)cc2)c1O</smiles><smiles></smiles>

(d)

FiguRE 1: Fructus psoraleae and prenylflavonoid structures: (a) psoralea plants, (b) psoralea flowers, (c) Chinese herbal product of fructus psoraleae, and (d) prenylflavonoid structures.

prenylflavonoids exhibited inhibitory effects on microsomal enzymes in in vitro experiments. For example, acyl CoA:cholesterol acyltransferase (ACAT), an enzyme that catalyzes the esterification of cholesterol in the intestine and the production of lipoproteins in the liver, was inhibited by bavachin and isobavachalcone [7]. The following are some similar reports: (1) neobavaisoflavone, isobavachalcone, bavachinin, corylifol A, and bakuchiol blocked human carboxylesterase 2 [8]; (2) bavachalcone, bavachin, and corylifol A strongly and neobavaisoflavone, isobavachalcone, and bavachinin moderately inhibiting UGT1A1 [9, 10]; and (3) psoralidin, isobavachalcone, and neobavaisoflavone inhibiting CYP2E1 mRNA expression. Meanwhile, isobavachalcone showed a weak competitive inhibition on CYP3A4, whereas psoralidin and neobavaisoflavone exhibited significant induction of CYP3A4 mRNA expression [11].
With the development of aging, senescent cells gradually accumulate in tissues, which produce proinflammatory factors and form a low-degree of sterility and potential systemic inflammation to result in aging-related diseases. This negatively affected microenvironment is called "inflammaging," which is the key factor connecting cell aging and the development of aging-related diseases. Modern pharmacological studies showed that bavachin, bavachinin, bavachalcone, isobavachalcone, and neobavaisoflavone (Figure 1(d)) had various pharmacological actions and could improve aging-related diseases. In this paper, we will review the effects and mechanisms of these five psoralea prenylflavonoids on ameliorating aging-related diseases, such as aginginduced chronic low-grade inflammation, cardiovascular dysfunction, diabetes, and obesity, and improving neurodegenerative diseases and osteoporosis. 


\section{Anti-Inflammatory Action}

The accumulation of senescent cells with age causes a series of pathological manifestations. Nonproliferating cells occupy key cell niches and produce proinflammatory factors, which form a negatively affected microenvironment and present a senescence-associated secretory phenotype (SASP). SASP contributes to a state of sterile, systemic, low-grade inflammation, also known as "inflammaging," which precedes many age-related diseases [12]. Considering the antiaging activity, a variety of synthetic and natural compounds has got keen interest in senolytic discovery (drugs selectively eliminating senescent cells) [13]. Fructus psoraleae is a traditional antiaging Chinese medical herb, and its resistance to "inflammaging" has become one of research concerns in antiaging field.

Psoraleae prenylflavonoids have been shown to suppress Toll-like receptor- (TLR-) or IL- $1 \beta$-induced inflammation response. Multiple reports indicated that isobavachalcone, bavachinin, and bavachin inhibit the expression of iNOS, COX-2, and mPGES-1 and the production of nitric oxide (NO) and prostaglandin $\mathrm{E}_{2}\left(\mathrm{PGE}_{2}\right)$ in microglia, macrophages, and chondrocytes [14-18]. Bavachin also inhibited $\mathrm{I} \kappa \mathrm{B} \alpha$ degradation and increased the nuclear translocation of p65 and p50 proteins in the inflammatory chondrocytes and endothelial cells $[19,20]$. In addition, bavachin significantly inhibited the activity and expression of matrix metalloproteinases (MMPs) and a disintegrin and metalloproteinase with thrombospondin motif (ADAMTS), while upregulating tissue inhibitors of metalloproteinases (TIMPs) in mouse chondrocytes [17]. These findings showed that bavachin has an anti-inflammatory effect on chondrocytes and could be used to treat articular cartilage degeneration $[17,19]$. Furthermore, bavachin has shown to attenuate LPS-induced inflammation and inhibit macrophage NLRP3 inflammasome activation. Bavachin suppressed caspase-1 activation, IL- $1 \beta$ secretion, and inflammasome complex formation [18]. Isobavachalcone can significantly downregulate the levels of intercellular adhesion molecule-1 (ICAM-1) and interferon- $\beta$ (IFN- $\beta$ ) and inhibit leukocyte adhesion to brain endothelial cells through inhibiting the TLR4/MyD88 signaling pathway [20]. Studies have determined that neobavaisoflavone significantly inhibits the production of reactive oxygen species, reactive nitrogen species, and cytokines in LPS+IFN- $\boldsymbol{\gamma}$ - or PMA-stimulated RAW264.7 macrophages, such as IL- $1 \beta$, IL-6, and tumor necrosis factor- (TNF-) $\alpha$ [21]. A previous study has shown that isobavachalcone, bavachin, bavachinin, and neobavaisoflavone also have inhibitory effects on IL-6-induced STAT3 promoter activity and phosphorylation in Hep3B cells [22].

Bavachinin attenuated HIF- $1 \alpha$ activity under hypoxia in a concentration-dependent manner and reduced HIF-1regulated transcription of genes related to energy metabolism, such as glucose transporter type 1 (Glut1) and hexokinase 2 [23]. HIF- $1 \alpha$ is the main oxygen sensor within cells and is essential to the regulation of cell responses to varying oxygen levels. The transcription factor HIF- $1 \alpha$ forms a complex relationship with inflammation and mitochondrial metabolism [24-27]. Recent studies have elucidated a new mechanism for mitochondrial metabolism to promote IL-
$1 \beta$ expression and activity via $\mathrm{HIF}-1 \alpha$ regulation $[25,28]$. Activated PKM2 inhibited the LPS-induced expression of HIF- $1 \alpha$ and IL- $1 \beta$, as well as a series of other HIF- $1 \alpha$-dependent genes. PKM2 induced by LPS forms a complex with HIF- $1 \alpha$ and directly binds to the IL- $1 \beta$ promoter. Researchers also observed that activated PKM2 inhibited LPS-induced glycolytic reprogramming and succinate production [28]. LPS-induced succinate stabilizes HIF- $1 \alpha$ which leads to activation of the proinflammatory cytokine IL- $1 \beta$ [25]. In obesity-related heart failure with preserved ejection fraction (HFpEF), HIF- $1 \alpha$ is responsible for recruiting M1 macrophages that mediate obesity-associated inflammation. M1 macrophages produce proinflammatory cytokines IL-6, monocyte chemoattractant protein-1 (MCP-1), TNF- $\alpha$, and IL- $1 \beta$ and increase the expression of thrombospondin, pro $\alpha 2$ (I) collagen, transforming growth factor (TGF) $\beta$, nicotinamide adenine dinucleotide phosphate (NADPH) oxidase, and connective tissue growth factor (CTGF) [29]. Therefore, the inhibition of HIF- $1 \alpha$ activity by bavachinin antagonized the inflammatory response under ischemia and hypoxia (Figure 2).

Prenylflavonoids also induced the expression and activity of transcription factors. For example, isobavachalcone antagonized lung injury and myotube atrophy by increasing the activity and expression of nuclear factor erythroid 2-related factor 2 (Nrf2) [30, 31]. Nrf2 is highly sensitive to oxidative stress, which is closely related to inflammatory response [32] and aging-related diseases, cardiovascular diseases, Alzheimer's and Parkinson's diseases, and rheumatic diseases [33-38]. Researchers demonstrated that Nrf2 inhibition of ROS-induced NLRP3 priming required the participation of $\mathrm{NAD}(\mathrm{P}) \mathrm{H}$ quinone dehydrogenase 1 (NQO1) [39]. Furthermore, the inhibition of Nrf2 also regulated the NLPR3 inflammasome formulation, assembly-mediated cleaved caspase-1, and IL- $1 \beta$ secretion through the Trx1/TXNIP complex [40]. In addition, Nrf2 binding to antioxidant responsive element (ARE) site can trigger the transcription of more than 200 endogenous protective genes, such as antioxidant, anti-inflammatory, and antiapoptotic genes [33, 41]. Therefore, the moderate expression and balance of $\mathrm{Nrf} 2$ promoted by prenylflavonoids are beneficial to the regulation of antioxidant, anti-inflammatory, and mitochondrial homeostasis (Figure 3).

Our latest study has shown that 4'-O-methybavachalcone significantly reduced cerebral infarction and edema, improved neurobehavioral indexes, inhibited the production of IL- $1 \beta$, TNF- $\alpha$, and IL- 6 in ischemic brain, and reduced the level of NLRP3, cleaved caspase1, and GSDMD-N (gasdermin D N-terminal domain) in the mouse stroke model and in oxygen glucose deprivation- (OGD-) RAW264.7 cells [42]. Recently, gasdermin D and NLRP3 have been identified as programmed death patterns of stroke cell inflammation and pyrolysis [43]. Moreover, a specific pyroptosis inhibitor Vx765 has a potential therapeutic value for cerebral ischemia by inhibiting the canonical inflammasome pathway of pyroptosis [44]. In brief, bavachalcone has the ability to inhibit the inflammatome NLRP3 activity and cell pyrolysis (Figure 3).

It has been reported that the bavachin activated gene expression of peroxisome proliferator-activated receptor 


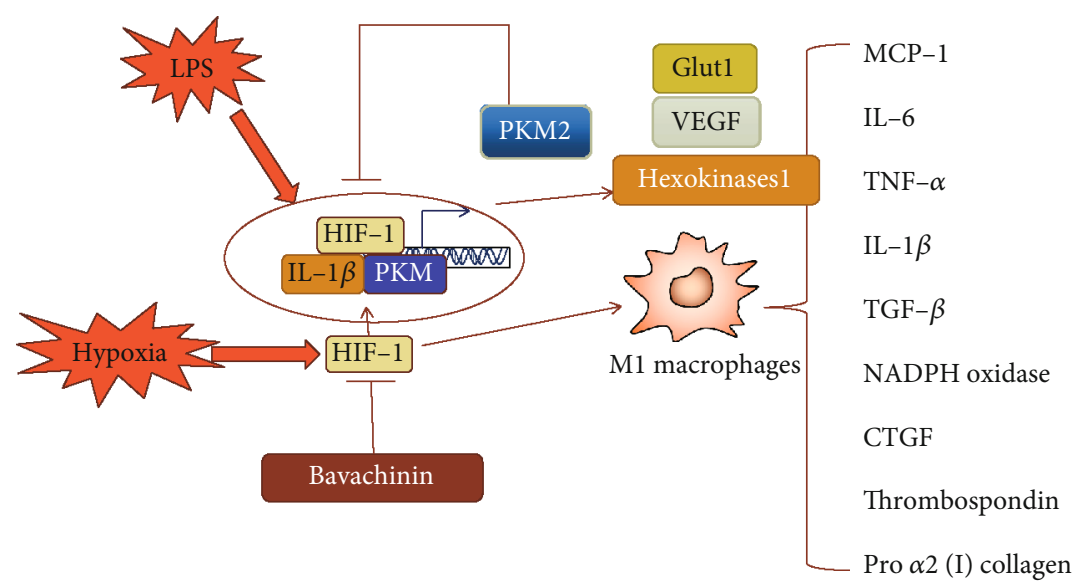

FIgURE 2: The schematic diagram of hypoxia/HIF-1 $\alpha$ signal transduction pathways inhibited by bavachinin in the anti-inflammation.

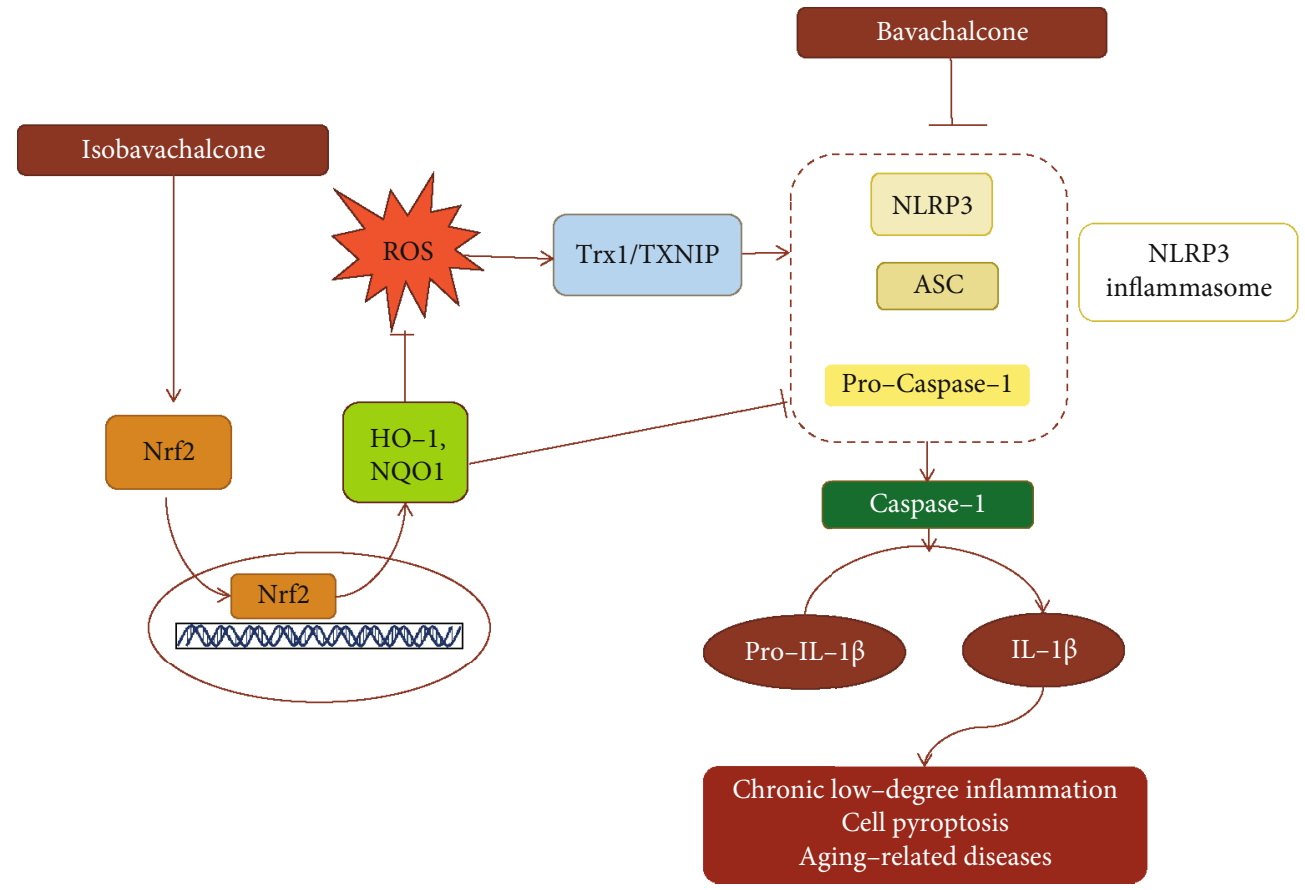

FIgURE 3: The schematic diagram of the Nrf2 signal transduction pathway activated by isobavachalcone and of NLRP3 inflammasome inhibited by bavachalcone in the anti-inflammation.

gamma $(\operatorname{PPAR} \gamma)$ [45]. As we all know, PPAR $\gamma$ can transform proinflammatory cytokines produced by neutrophils, platelets, and macrophages into anti-inflammatory mediators. PPAR $\gamma$ and its ligands further regulate platelet and neutrophil function, reduce trafficking, promote neutrophil apoptosis, and prevent platelet-leukocyte interactions. PPAR $\gamma$ alters macrophage transport, increases efferocytosis and phagocytosis, and promotes macrophages to switch to M2-type polarity [46]. What is more, endothelial PPAR $\gamma$ is an indispensable factor to prevent endothelial dysfunction with aging [47], and interference with PPAR $\gamma$ function can accelerate vascular aging and atherosclerosis [48, 49]. Conversely, cell senescence may also alter the PPAR $\gamma$-dependent fatty acid handling in human microvascular endothelial cells and contribute to inflammation [50].
In the following summary (Table 1), the cell or animal models, inflammation induction methods, active recipients, experimental doses, and pharmacological effects in more detail are provided. In general, prenylflavonoids inhibited JNK1/2, ERK1/2, NF- $\kappa$ B, STAT3, inflammatome NLRP3 activity, iNOS and mPGES-1 expression, secretion of many cytokines, and cell pyroptosis. These findings indicate that psoralea prenylflavonoids have the potential effects on improving "inflammaging" environment and aging-related diseases.

\section{Cardiovascular Function Regulation}

The age-related status changes lead to low-degree inflammation and increase of oxidative stress in the cardiovascular system. The phenotypes of these changes include rigidity of 
TABLE 1: Summary of anti-inflammation experiments of five psoralea prenylflavonoids.

\begin{tabular}{lcccc}
\hline Cells or animals & $\begin{array}{c}\text { Model } \\
\text { method }\end{array}$ & Active ingredient & Dosage & Pharmacological effect \\
\hline
\end{tabular}

(i) Concentration-dependent inhibitory effects on $\mathrm{NO}$ and $\mathrm{PGE}_{2}$ production with an $\mathrm{IC}_{50}$ for inhibiting NO production: $1.6 \pm 0.11 \mu \mathrm{mol} / \mathrm{L}$

BV-2 microglia LPS Isobavachalcone $2,5,10 \mu \mathrm{mol} / \mathrm{L}$

(ii) Blocked the I- $\kappa \mathrm{B} \alpha$ degradation and downregulated NF- $\kappa \mathrm{B}$ activity

(iii) Inhibited the iNOS and COX-2 mRNA and protein expression

\begin{tabular}{lcccc}
\hline $\begin{array}{l}\text { RAW264.7 murine } \\
\text { monocytic cells }\end{array}$ & $\begin{array}{c}\text { MALP-2; } \\
\text { LPS } \\
\text { Poly[I:C] }\end{array}$ & Isobavachalcone & 20,50,100 $\mu \mathrm{mol} / \mathrm{L}$ & $\begin{array}{c}\text { (i) Inhibited iNOS expression in luciferase } \\
\text { reporter and protein level induced by TLRs } \\
\text { agonists and inhibited nitrite production }\end{array}$ \\
\hline Microglial cells & LPS & $\begin{array}{c}\text { Bavachinin } \\
\text { Isobavachalcone } \\
\text { Neobavaisoflavone }\end{array}$ & $\begin{array}{c}1,3,10,30, \\
100 \mu \mathrm{mol} / \mathrm{L}\end{array}$ & $\begin{array}{c}\text { (i) Concentration-dependent inhibitory effects on } \\
\text { NO production with an } \mathrm{IC}_{50}: 26 \mu \mathrm{mol} / \mathrm{L} \\
\text { (bavachinin), } 17 \mu \mathrm{mol} / \mathrm{L} \text { (isobavachalcone), } \\
29 \mu \mathrm{mol} / \mathrm{L} \text { (neobavaisoflavone) }\end{array}$ \\
\hline
\end{tabular}

$\begin{array}{lccc}\begin{array}{l}\text { bEnd.3 murine brain } \\ \text { endothelial cells }\end{array} & \begin{array}{l}\text { MALP-2; } \\ \text { LPS }\end{array} & \text { Isobavachalcone } & 0.1,1,5 \mu \mathrm{mol} / \mathrm{L}\end{array}$

(i) Downregulated ICAM-1 mRNA and protein expression

(iii) Dose-dependently attenuated the adhesion of monocytes to endothelial cells activated by LPS

(i) Decreased $\mathrm{I} \kappa \mathrm{B} \alpha$ kinase and NF- $\kappa \mathrm{B}$ DNA-

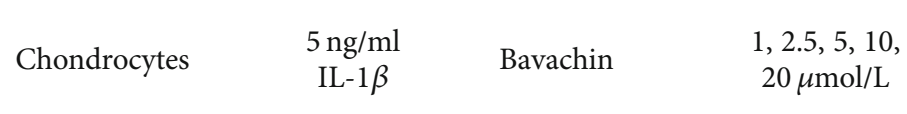
binding activity

(ii) Inhibited IL- $1 \beta$-induced RANTES, MCP-2,

MIP1- $\alpha$, and MIP1- $\beta$ chemokine production

(iii) Reduced migration of THP-1 monocytic cells

(i) Upregulated aggrecan and collagen type II expression in a dose-dependent manner

(ii) Inhibited MMP-1/3/13, and ADMATS-4/5

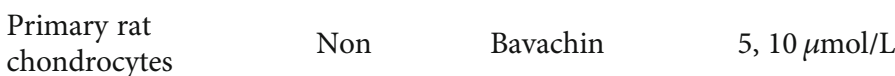

expression, and upregulated TIMP-1/2/3/4

expression

(iii) Inhibited iNOS and COX-2 expression and downregulated $\mathrm{NO}$ and $\mathrm{PGE}_{2}$ in a dosedependent manner

(i) Inhibited iNOS and mPGES-1 expression and downregulated $\mathrm{NO}$ and $\mathrm{PGE}_{2}$ in a dosedependent manner

Murine J774A.1 cells

and murine

peritoneal macrophages $\begin{array}{ll}\text { LPS Bavachin } & 10,20,30, \\ 40 \mu \mathrm{mol} / \mathrm{L}\end{array}$

(ii) Inhibited phosphorylation of JNK $1 / 2$ and

\begin{tabular}{|c|c|c|}
\hline $\begin{array}{l}\text { RAW264.7 } \\
\text { macrophages }\end{array}$ & $\begin{aligned} & \text { LPS } \\
+ & \text { IFN }-\gamma\end{aligned}$ & Neobavaisoflavone \\
\hline
\end{tabular}

Bavachin Bavachinin Hep3B cells
IL-6
$0.05 \mu \mathrm{mol} / \mathrm{L}$ (bavachin), $3.02 \pm 0.53 \mu \mathrm{mol} / \mathrm{L}$ (bavachinin), $2.45 \pm 0.13 \mu \mathrm{mol} / \mathrm{L}$

(isobavachalcone), $2.77 \pm 0.02 \mu \mathrm{mol} / \mathrm{L}$ (neobavaisoflavone) ERK $1 / 2$, and downregulated NF- $\kappa$ B activity (iii) Suppressed production of IL- $\beta$ and the expression of NLRP3 inflammasome complex (iv) Inhibited production of NO, IL-6 and IL-12p40 in LPS-stimulated murine peritoneal macrophages

(i) Inhibited the production of ROS, RNS, and cytokines: IL- $1 \beta$, IL-6, IL-12p40, IL-12p70, and

TNF- $\alpha$ with $\mathrm{ED}_{50}: 25.00 \mu \mathrm{mol} / \mathrm{L}(\mathrm{NO})$;

$23.11 \mu \mathrm{mol} / \mathrm{L}$ (IL-1 $\beta$ ); $5.03 \mu \mathrm{mol} / \mathrm{L}$ (IL-6); $5.23 \mu \mathrm{mol} / \mathrm{L}$ (IL-12p40); $5.26 \mu \mathrm{mol} / \mathrm{L}$ (IL-12p70); $18.80 \mu \mathrm{mol} / \mathrm{L}(\mathrm{TNF}-\alpha)$

(i) Inhibited STAT3 phosphorylation with an $\mathrm{IC}_{50}$ for STAT3-dependent promoter activity: $4.89 \pm$
$10,30,60 \mu \mathrm{mol} / \mathrm{L}$ 
TABLE 1: Continued.

\begin{tabular}{|c|c|c|c|c|c|}
\hline Cells or animals & $\begin{array}{l}\text { Model } \\
\text { method }\end{array}$ & Active ingredient & Dosage & Pharmacological effect & $\begin{array}{c}\text { Reference } \\
\text { number }\end{array}$ \\
\hline Male ICR mice & $\begin{array}{l}\text { Ischemic } \\
\text { stroke }\end{array}$ & $\begin{array}{c}4^{\prime}-\mathrm{O}- \\
\text { methybavachalcone }\end{array}$ & $\begin{array}{c}5,10,20 \mathrm{mg} / \mathrm{kg} \text {, oral } \\
\text { gavage after animal } \\
\text { modeling, daily }\end{array}$ & $\begin{array}{l}\text { (i) Improved the area of cerebral infarction, brain } \\
\text { edema, and neurobehavioral indexes } 48 \text { hours } \\
\text { after MCAO/R } \\
\text { (ii) Lowered active-PARP and cleaved-caspase-3 } \\
\text { levels } \\
\text { (iii) Inhibited IL-1 } \beta \text {, TNF- } \alpha \text {, and IL- } 6 \text { production } \\
\text { in ischemic cerebral homogenate } \\
\text { (iv) Reduced NLRP3/GSDMD-mediated } \\
\text { pyroptosis of brain tissue and cells }\end{array}$ & {$[43]$} \\
\hline
\end{tabular}

elastic arteries, endothelial dysfunction, hypoperfusion cerebral ischemia, stroke, and cardiac diastolic dysfunction. This involves the Klotho longevity gene, the AMPK energysensitive pathway, and the activity and expression of eNOS, MnSOD, and PGC- $1 \alpha$ genes.

The cardiovascular protective effects of prenylflavonoid derivatives from fructus psoraleae have been reported (Table 2). Kassahun et al. [51] reported that isobavachalcone inhibited hTRPC3 current, which significantly relaxes the contraction of the endothelium-intact aortic rings induced by phenylephrine. In addition, a previous study has shown that isobavachalcone inhibits platelet aggregation induced by arachidonic acid, collagen, and platelet activating factor in rabbits [52]. As we all know, platelet aggregation is closely related to myocardial infarction and stroke $[53,54]$.

Acyl-CoA:cholesterol acyltransferase (ACAT), a key enzyme regulating cholesterol esterification, induced the accumulation of cholesterol esters in the endoplasmic reticulum of macrophages and smooth muscle cells and promoted the formation of foam cells $[55,56]$. However, the enzyme was inhibited by isobavachalcone and bavachin in an ACAT noncompetitive inhibition type [7]. In in vitro studies performed by our team in human endothelial cells, bavachalcone suppressed cell senescence by decreasing the activity of a senescence-associated $\beta$-galactosidase (a senescent markers) and downregulating mRNA expression of p16 (ink4a) (a marker of replicative senescence) and IL- $1 \alpha$ (a proinflammatory cytokine of SASP) [57]. Bavachalcone also activated retinoid-related orphan receptor alpha $1(\mathrm{ROR} \alpha 1)$ reporter gene activity and induced ROR $\alpha 1$ mRNA expression in a dose-dependent manner, resulting in the enhancement of the amplitude of circadian rhythm of Bmal1 mRNA expression after serum shock [57]. Another study has shown that bavachalcone protected endothelial cells by increasing the activity of adenosine $5^{\prime}$-monophosphate-activated protein kinase (AMPK) and the expression of manganese-superoxide dismutase (MnSOD) and PGC- $1 \alpha$, inhibiting mitochondrial oxidative stress and improving mitochondrial biogenesis [58]. We also have found that bavachalcone promoted endothelial progenitor cell (EPC) differentiation and neovascularization through the AMPK pathway. Oral administration of bavachalcone for 14 days stimulated neovascularization and reestablishment of microcirculation in a rat ischemic hind limb model. The number of EPCs and the level of erythropoietin (EPO) in the circulation were increased in rats with bavachalcone treatment. Furthermore, bavachalcone enhanced the activity of ROR $\alpha 1$ and EPO reporter genes [59]. Bahlmann et al. [60] reported that the treatment of recombinant human EPO caused a significant mobilization of circulating CD34(+)/CD45(+) EPC in the peripheral blood and increased the number of functionally active EPCs in patients and healthy subjects. Previous clinical studies and animal experiments also have shown that EPO therapy increased the number of circulating EPCs and promoted homing and improved acute myocardial infarction, heart failure, stroke, and cerebral aneurysm [61-64]. Our multiple results indicate (Figure 4) that AMPK-mediated cardiovascular protection of bavachalcone can include regulating mitochondrial biogenesis [65], delaying cell senescence [66], activating eNOS, MnSOD and PGC- $1 \alpha$ activity and expression $[67,68]$, and promoting EPC differentiation [69], which presents consistency with the results of other research groups.

\section{Diabetes and Obese Intervention}

Aging, diabetes, and obesity had a synergistic effect on inflammation and oxidative stress among the elderly, which in turn increased the risk of diabetes and obesity. Early interventions to reduce inflammation, oxidative stress, and insulin resistance may improve age-related diseases [70-73]. Fructus psoraleae, as an option for seeking treatment and prevention of diabetes and obesity, has the potential to improve the active life expectancy of the elderly.

A recent report revealed that psoralea prenylflavonoid extract (PFE) significantly reduced body weight and fat mass in a dose-dependent manner, increased energy expenditure, improved insulin sensitivity, and prevented hepatic steatosis by increasing lipid oxidation and secretion in high-fat dietfed mice. The study also found that PFE induced clear browning in subcutaneous white adipose tissue, increased brown adipose tissue activity, and thermogenic genes [74]. Another research group also reported that the extract of Psoralea corylifolia seeds attenuated methylglyoxal-induced insulin resistance and significantly increased the phosphorylation of Akt, IRS-1/2, and glucose uptake [75]. Moreover, this extract reduced nonalcoholic fatty liver disease, the expression of lipogenic, and inflammatory genes, such as TNF- $\alpha$, IL-1 $\beta$, and iNOS in high-fat diet-induced obese mice [76]. In addition, Lee et al. [45] showed that bavachin $(2 \mu \mathrm{M})$ increased the expression and secretion of adiponectin and 
TABLE 2: Experimental summary of five psoralea prenylflavonoids improving aging-related diseases.

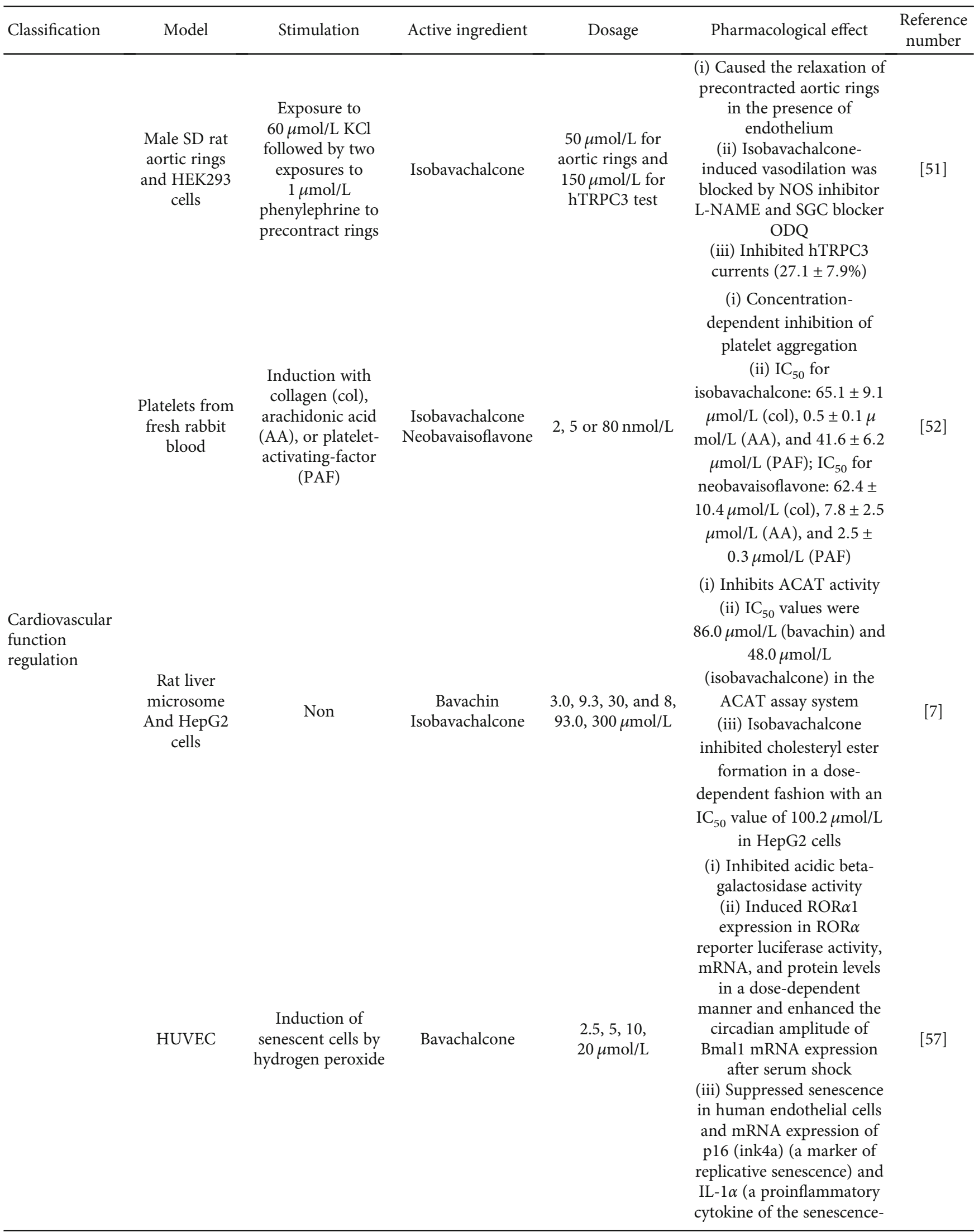


TABle 2: Continued.

\begin{tabular}{|c|c|c|c|c|c|c|}
\hline Classification & Model & Stimulation & Active ingredient & Dosage & Pharmacological effect & $\begin{array}{c}\text { Reference } \\
\text { number }\end{array}$ \\
\hline & HUVEC & $\begin{array}{c}\text { Induction of } \\
\text { senescent cells by } \\
\text { hydrogen peroxide }\end{array}$ & Bavachalcone & $1,2,5 \mu \mathrm{mol} / \mathrm{L}$ & $\begin{array}{l}\text { associated secretory } \\
\text { phenotype) } \\
\text { (i) Inhibited acidic beta- } \\
\text { galactosidase activity } \\
\text { (ii) Promoter and increased } \\
\text { MnSOD mRNA and } \\
\text { protein expressions } \\
\text { (iii) Suppressed the } \\
\text { mitochondrial superoxide } \\
\text { production in endothelial } \\
\text { cells } \\
\text { (iv) Stimulated liver kinase } \\
\text { B1 and AMPK } \alpha \\
\text { phosphorylation } \\
\text { (v) AMPK knockdown by } \\
\text { shRNA-AMPK reversed } \\
\text { the effects of bavachalcone } \\
\text { on MnSOD }\end{array}$ & [58] \\
\hline & $\begin{array}{c}\text { (1) HUVECs } \\
\text { (2) EA.hy926 } \\
\text { cells } \\
\text { (3) Rat bone } \\
\text { marrow } \\
\text { mesenchymal } \\
\text { cells } \\
\text { (4) Male } \\
\text { Wistar rat }\end{array}$ & $\begin{array}{c}\text { Rat ischemic } \\
\text { hindlimb model }\end{array}$ & Bavachalcone & $\begin{array}{l}1,2,5 \mu \mathrm{mol} / \mathrm{L} \text { for } \\
\text { cell culture and } \\
3 \mathrm{mg} / \mathrm{kg} \text { daily } \\
\text { intragastric } \\
\text { administration for } \\
\text { in vivo experiments }\end{array}$ & $\begin{array}{l}\text { (i) Low-dose bavachalcone } \\
\text { administered orally for } 14 \\
\text { days stimulated the } \\
\text { recovery of ischemic } \\
\text { hindlimb blood flow in rat } \\
\text { hindlimb ischemia models } \\
\text { (ii) Increased circulating } \\
\text { EPCs and promoted } \\
\text { capillary angiogenesis } \\
\text { (iii) Bavachalcone } \\
\text { treatment of rat bone } \\
\text { marrow cells for } 24 \mathrm{~h} \\
\text { initiated the AMP-activated } \\
\text { protein kinase activity } \\
\text { (iv) Enhanced the activity } \\
\text { of ROR } \alpha 1 \text { and EPO } \\
\text { luciferase reporter gene } \\
\text { (v) Bavachalcone treatment } \\
\text { elevated EPO mRNA and } \\
\text { protein expression in vitro } \\
\text { and in vivo and the } \\
\text { circulating EPO levels in } \\
\text { rats } \\
\text { (vi) Bavachalcone induced } \\
\text { differentiation of bone } \\
\text { marrow cells into } \\
\text { endothelial progenitor cells } \\
\text { (vii) Increased number of } \\
\text { EPCs and the level of EPO } \\
\text { in the circulation in rats }\end{array}$ & [59] \\
\hline \multirow[t]{2}{*}{$\begin{array}{l}\text { Diabetes and } \\
\text { obese } \\
\text { intervention }\end{array}$} & $\begin{array}{l}\text { Mouse 3T3- } \\
\text { L1 pre- } \\
\text { adipocytes }\end{array}$ & $\begin{array}{l}\text { Media containing } \\
\text { MDI }(1 \mu \mathrm{g} / \mathrm{mL} \\
\text { isobutyl- } \\
\text { methylxanthine, } \\
1 \mu \mathrm{M} \\
\text { dexamethasone, and } \\
1 \mu \mathrm{g} / \mathrm{mL} \text { insulin })\end{array}$ & Bavachin & $2 \mu \mathrm{mol} / \mathrm{L}$ & $\begin{array}{l}\text { (i) Increased the expression } \\
\text { and secretion of } \\
\text { adiponectin } \\
\text { (ii) Enhanced glucose } \\
\text { uptake via GLUT4 } \\
\text { translocation }\end{array}$ & [45] \\
\hline & $\begin{array}{l}\text { 9-week-old } \\
\text { female } \mathrm{db} / \mathrm{db} \\
\text { mice }\end{array}$ & High-fat diet & Bavachinin & $\begin{array}{c}50 \text { and } \\
100 \mathrm{mg} / \mathrm{kg} / \text { day }\end{array}$ & $\begin{array}{l}\text { (i) Bavachinin dose- } \\
\text { dependently induced the } \\
\text { transcriptional activities of }\end{array}$ & {$[80]$} \\
\hline
\end{tabular}


TABle 2: Continued.

\begin{tabular}{|c|c|c|c|c|c|c|}
\hline Classification & Model & Stimulation & Active ingredient & Dosage & Pharmacological effect & $\begin{array}{c}\text { Reference } \\
\text { number }\end{array}$ \\
\hline & $\begin{array}{l}\text { 3T3-L1 } \\
\text { preadipocytes } \\
\text { and Zebrafish }\end{array}$ & $\begin{array}{l}\text { Media containing } \\
\text { MDI }(1 \mu \mathrm{g} / \mathrm{mL} \\
\text { isobutyl- } \\
\text { methylxanthine, } \\
1 \mu \mathrm{M} \\
\text { dexamethasone, and } \\
1 \mu \mathrm{g} / \mathrm{mL} \text { insulin })\end{array}$ & Isobavachalcone & $2,10,40 \mu \mathrm{mol} / \mathrm{L}$ & $\begin{array}{l}\text { the mouse ligand-binding } \\
\text { domain of PPAR } \gamma \text { and } \\
\text { PPAR } \alpha \\
\text { (ii) Ameliorates diabetes } \\
\text { and hyperlipidaemia in } \\
\text { db/db and in diet-induced } \\
\text { obese mice } \\
\text { (iii) Decreased lipid } \\
\text { accumulation in liver in } \\
\text { db/db and in diet-induced } \\
\text { obese mice } \\
\text { (iv) Regulates PPAR gene } \\
\text { expression in vitro and } \\
\text { in vivo } \\
\text { (v) Occupies a novel } \\
\text { alternative binding site in } \\
\text { addition to the canonical } \\
\text { site of synthetic agonists of } \\
\text { PPAR } \gamma \\
\text { (i) Decreased protein levels } \\
\text { of PPAR } \gamma \text { and C/EBP } \alpha \\
\text { (ii) Gene expression levels } \\
\text { of SREBP1c, adiponectin, } \\
\text { ACC1, and FAS } \\
\text { (iii) Inhibited adipogenesis } \\
\text { and prevents lipid } \\
\text { accumulation in high } \\
\text { cholesterol-diet Zebrafish } \\
\text { larvae }\end{array}$ & {$[81]$} \\
\hline \multirow[t]{3}{*}{ Neuroprotection } & $\begin{array}{c}\text { BV-2 } \\
\text { microglia }\end{array}$ & $\begin{array}{c}\text { LPS } \\
450 \mu \mathrm{mol} / \mathrm{L} \text { of } \mathrm{H}_{2} \mathrm{O}_{2} \\
\text { solution }\end{array}$ & $\begin{array}{c}\text { Bavachin } \\
\text { Bavachinin } \\
\text { Bavachalcone } \\
\text { Isobavachalcone }\end{array}$ & $1,10,100 \mu \mathrm{mol} / \mathrm{L}$ & $\begin{array}{c}\text { (i) Inhibited } \\
\text { neuroinflammation, } \\
\text { oxidative damage, and key } \\
\text { AD-related protein targets } \\
\text { in BV-2 microglia } \\
\text { (ii) Inhibited } \beta \text {-secretase } \\
\text { (BACE-1), glycogen } \\
\text { synthase kinase } 3 \beta \text { (GSK- } \\
3 \beta \text { ), and } \\
\text { acetylcholinesterase } \\
\text { (AChE) expression } \\
\text { (iii) Bavachalcone and } \\
\text { isobavachalcone exhibited } \\
\text { strong inhibitory activities } \\
\text { on } \mathrm{A} \beta 42 \text { aggregation }\end{array}$ & {$[82]$} \\
\hline & $\begin{array}{l}\text { SH-SY5Y cell } \\
\text { Yeast two } \\
\text { hybrid }\end{array}$ & $\mathrm{A} \beta 42$ & $\begin{array}{c}\text { Isobavachalcone } \\
\text { (IBC) } \\
\text { Bavachinin (BCN) }\end{array}$ & $\begin{array}{c}3 \mu \mathrm{mol} / \mathrm{L}(\mathrm{IBC}) \text { and } \\
30 \mu \mathrm{mol} / \mathrm{L}(\mathrm{BCN})\end{array}$ & $\begin{array}{c}\text { (i) Inhibited } \mathrm{A} \beta 42 \\
\text { aggregation } \\
\text { (ii) Attenuated } \mathrm{A} \beta 42- \\
\text { induced cell toxicity }\end{array}$ & {$[83]$} \\
\hline & $\begin{array}{c}\text { Mouse BV-2 } \\
\text { cells } \\
\text { Neuro-2a cells } \\
\text { Male C57BL/6 } \\
\text { mice }\end{array}$ & $\begin{array}{c}\text { LPS } \\
\text { Preadministration } \\
\text { of MPTP }(20 \mathrm{mg} / \mathrm{kg})\end{array}$ & Isobavachalcone & $\begin{array}{c}0.1,1,5,10 \\
20 \mu \mathrm{mol} / \mathrm{L} \\
50 \mathrm{mg} / \mathrm{kg}\end{array}$ & $\begin{array}{l}\text { (i) Improved the motor, } \\
\text { balance, and coordination } \\
\text { abilities of PD mouse } \\
\text { (ii) Inhibited the activation } \\
\text { of microglia and astrocytes } \\
\text { and the necrosis of neurons } \\
\text { injured by MPTP } \\
\text { (iii) Decreased the levels of } \\
\text { IL- } 6 \text { and IL- } 1 \beta \text { in PD } \\
\text { mouse and of TNF- } \alpha \text {, IL- } 6 \text {, }\end{array}$ & {$[84]$} \\
\hline
\end{tabular}


TABle 2: Continued.

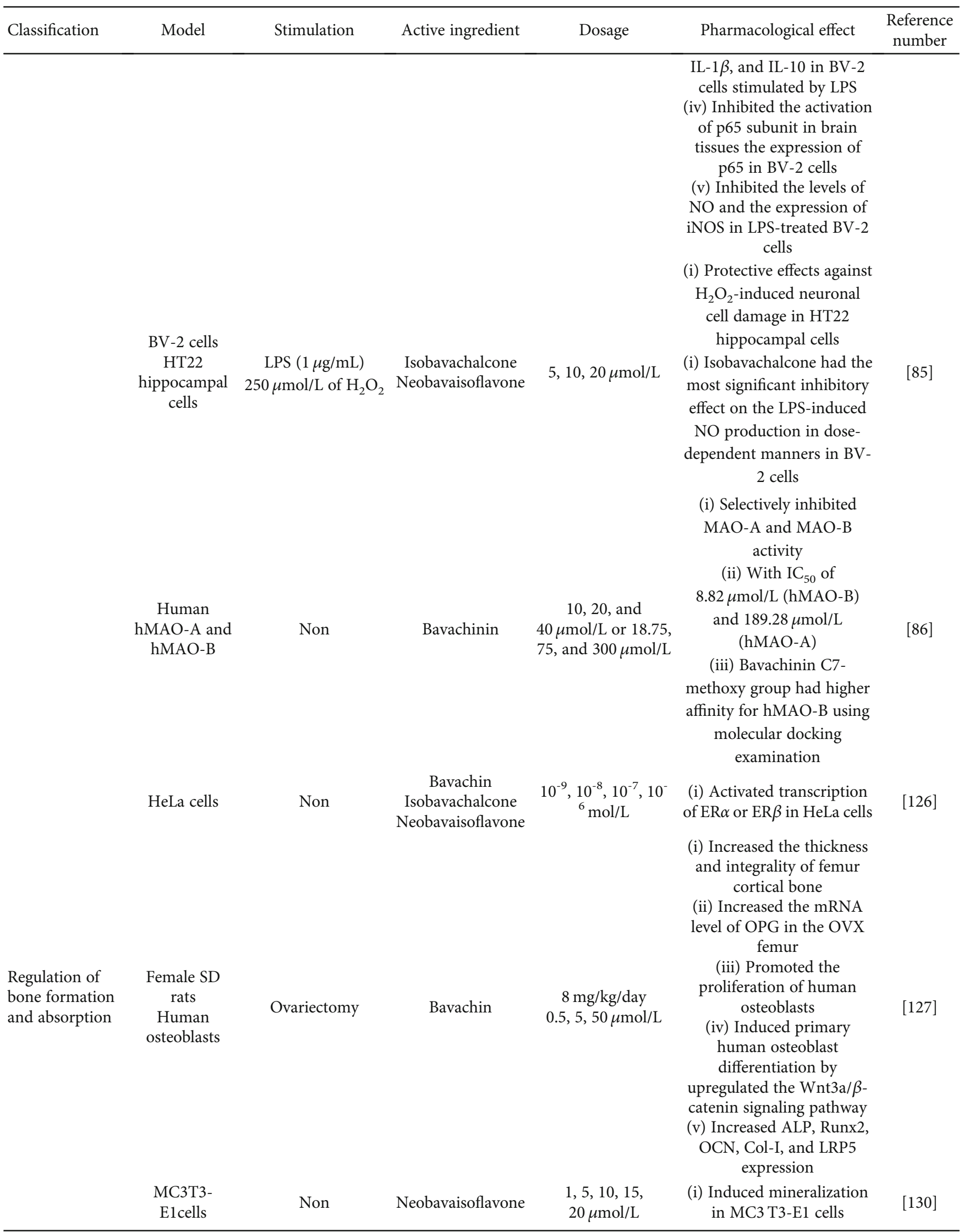


TABLE 2: Continued.

\begin{tabular}{|c|c|c|c|c|c|c|}
\hline Classification & Model & Stimulation & Active ingredient & Dosage & Pharmacological effect & $\begin{array}{c}\text { Reference } \\
\text { number }\end{array}$ \\
\hline & $\begin{array}{c}\text { Bone marrow- } \\
\text { derived } \\
\text { macrophages }\end{array}$ & $\begin{array}{c}\text { RANKL } \\
\text { Vitamin D3 }\left(10^{-6}\right. \\
\text { mol/L) and PGE2 } \\
\left(10^{-8} 2 \mathrm{~mol} / \mathrm{L}\right)\end{array}$ & Bavachalcone & $0.5,1,2,5 \mu \mathrm{mol} / \mathrm{L}$ & $\begin{array}{l}\text { (ii) Upregulated the } \\
\text { expression of Runx2 and } \\
\text { Osx } \\
\text { (i) Induced activation of } \\
\text { ALP, the expression of Col- } \\
\text { I, OCN, and BSP } \\
\text { (i) Inhibited } \\
\text { osteoclastogenesis in } \\
\text { coculture of whole bone } \\
\text { marrow cells and calvarial } \\
\text { osteoblasts and inhibited } \\
\text { bone resorption } \\
\text { (ii) With the IC }{ }_{50} \text { of } \\
\text { approximately } 1.5 \mu \text { mol/L } \\
\text { (iii) Suppressed the } \\
\text { expression of c-Fos and } \\
\text { NFATc1 by RANKL } \\
\text { (iv) Reduced activation of } \\
\text { MEK, ERK, and Akt by } \\
\text { RANKL }\end{array}$ & [135] \\
\hline
\end{tabular}

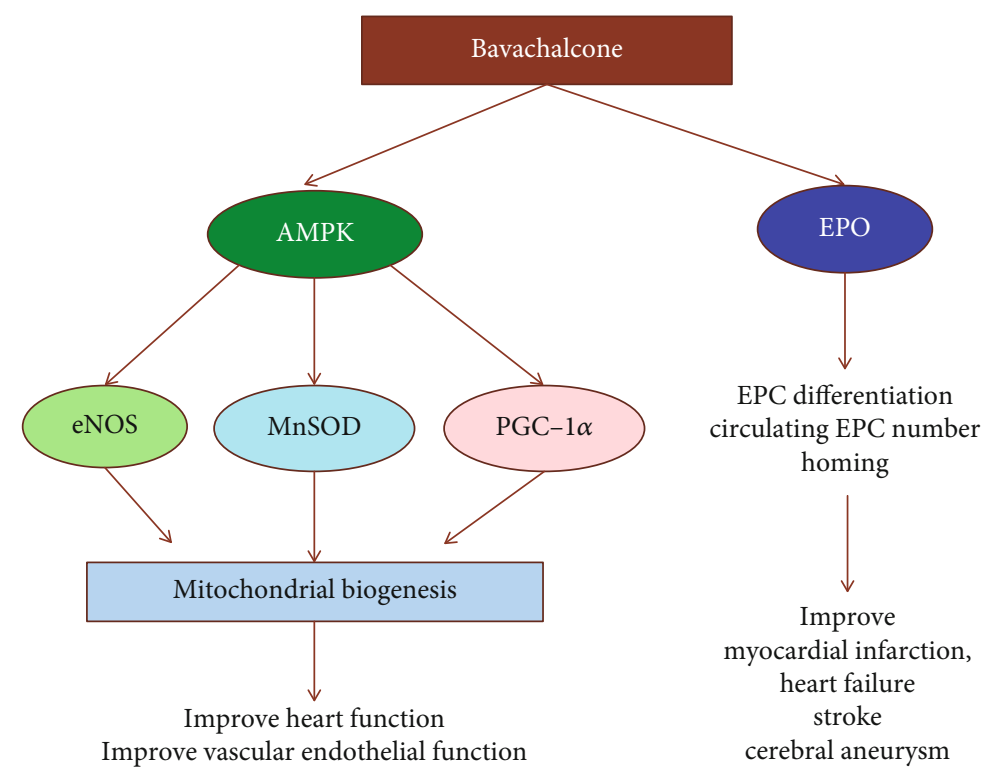

FIGURE 4: The schematic diagram of bavachalcone improving cardiovascular function by activating AMPK and promoting EPO expression.

enhanced glucose uptake via GLUT4 translocation by activating the protein kinase $\mathrm{B}$ (Akt) and AMPK pathway in the presence or absence of insulin. Targeting the AMPK signaling pathway is one of the target pathways to control diabetes. Some studies have shown that diabetic patients have impaired AMPK activity, and metformin, which is used to treat diabetes, works by regulating AMPK. Natural medicines of plant origin showed great potential in regulating and activating the AMPK pathway and can be used as drug candidates for the treatment of diabetes and its complications $[77,78]$.
Moreover, bavachin promoted lipid accumulation in 3T3-L1 cells at differentiation day 8 by activating gene expression of peroxisome proliferator-activated receptor gamma $(\operatorname{PPAR} \gamma)$ and CCAAT/enhancer binding protein alpha $(\mathrm{C} / \mathrm{EBP} \alpha)[45]$, suggesting that bavachin might have therapeutic potential for type 2 diabetes. Like bavachin, bavachinin is a PPAR $\gamma$ agonist. Isolated bavachinin is a mixture of $S$ and $R$ configurations. A time-resolved fluorescence resonance energy transfer-based competitive binding assay showed that $(S)$ - and (R)-bavachinin had similar PPAR $\gamma$ 
agonist activities with $\mathrm{IC}_{50} 616.7 \mathrm{nM}$ and $471.2 \mathrm{nM}$, respectively [79]. Subsequent in vivo studies have shown that bavachinin exhibited blood glucose-lowering properties without causing weight gain and liver toxicity. Importantly, bavachinin had synergistic effects with the synthetic PPAR $\gamma$ agonist thiazolidinediones and $\operatorname{PPAR} \alpha$ agonist fibrates, which induced PPAR transcriptional activity, as well as lowered glucose and triacylglycerol levels in $\mathrm{db} / \mathrm{db}$ mice [80]. Further research found that bavachinin bound not only to the canonical site of PPAR agonists but also to a novel alternative binding site. Moreover, rosiglitazone pretreatment prevented bavachinin from binding to the canonical site instead of a novel alternative binding site [80]. The sketch of bavachinin activating PPARs to improve insulin resistance and obesity is shown in Figure 5.

Isobavachalcone caused 3T3-L1 cell cycle arrest at G0/G1 and dose-dependently inhibited the protein expression levels of cyclin D1, cdk4, and cd6 within $48 \mathrm{~h}$ after adipocyte differentiation medium MDI stimulation. Moreover, while isobavachalcone inhibited adipocyte fat accumulation, it also reduced intrahepatic fat deposition and hepatic steatosis in zebrafish fed high fat cholesterol diets [81]. Table 2 summarizes the experimental data related to diabetes and obesity.

\section{Neuroprotection}

Aging is the most important independent risk factor for neurodegenerative diseases. Millions of people suffer from Alzheimer's disease (AD), Parkinson's disease (PD), vascular dementia (VD), and ischemic stroke around the world. Fructus psoraleae is a promising antiaging Chinese herb which is introduced for the therapy of neurodegenerative diseases. Several studies have demonstrated that Psoralea corylifolia seed extracts can exert neuroprotection in vivo and in vitro. Alzheimer's disease (AD) is an age-related neurodegenerative disease. Evidence showed that four components of Psoralea corylifolia, named bavachin, bavachinin, bavachalcone, and isobavachalcone, differentially inhibited neuroinflammation, oxidative damage, and key $\mathrm{AD}$-related protein targets, such as amyloid $\beta$-peptide $42, \beta$-secretase, glycogen synthase kinase $3 \beta$, and acetylcholinesterase in vivo [82]. The researchers further revealed that isobavachalcone and bavachinin regulate the aggregation of a $\beta 42$ through different mechanisms. Isobavachalcone significantly inhibited both oligomerization and fibrillization of $\mathrm{A} \beta 42$, whereas bavachinin inhibited fibrillization and led to off-pathway aggregation. Both of the compounds attenuated $\mathrm{A} \beta 42-$ induced toxicity in an SH-SY5Y cell model [83]. Meanwhile, isobavachalcone can also effectively relieve Parkinson's disease (PD) induced by 1-methyl-4-phenyl-1,2,3,6-tetrahydropyridine (MPTP), prolong the residence time of mice on Rota-rod, and alleviate the neuronal necrosis [84]. Isobavachalcone also inhibited the activation of microglia and decreased the expression of IL- 6 and IL- $1 \beta$ in the brain of $\mathrm{PD}$ mice [80]. In vitro, isobavachalcone significantly suppressed BV-2 microglia activation and the NO production induced by LPS [84], while neobavaisoflavone had a strong inhibitory activity on $\mathrm{H}_{2} \mathrm{O}_{2}$-induced cell death in HT22 hippocampal cells [85]. Monoamine oxidase $\mathrm{B}$ (MAO-B) is an enzyme that breaks down dopamine in the brain. MAO$\mathrm{B}$ inhibitors block the action of the enzyme and therefore improve the symptoms in early PD. A molecular docking test found that the $\mathrm{C} 7$ methoxy group of bavachinin has a high affinity for MAO-B, suggesting that bavachinin might be a selective and competitive human MAO-B inhibitor and could be used in the PD treatment [86]. The experimental details are summarized in Table 2.

Recently, bavachinin was identified as a novel agonist that activates all three PPAR isoforms, so-called pan-PPAR agonist [80], which indicated its potentially powerful application of prenylflavonoids in neuroprotection. PPAR $\gamma$ agonists have been demonstrated as neuroprotective agents. Pioglitazone and 15d-prostaglandin J2 significantly reduced the infarct volume, attenuated the aggregation of parenchymal neutrophils, decreased the release of TNF- $\alpha$, IL- $1 \beta$, and IL6 , and improved neurological function in the cerebral ischemia injury mice $[87,88]$; reduced $\beta$-amyloid levels effectively reversed cerebrovascular damage, improved energy metabolism and antioxidant capacity of model mice's cortex, and inhibited $\beta$-amyloid-stimulated COX-2, TNF- $\alpha$, and IL- 6 expression in Alzheimer's disease models [89-91]. Pioglitazone and MDG548 also increased the phagocytosis of microglia on necrotic cells, reduced the death of dopaminergic neurons and the production of cellular reactive oxygen species, upregulated the expression of MRC1, CD68, and IL-10, elevated the activity of glutathione-S-transferase, and blocked the activity of monoamine oxygenase $\mathrm{B}$ in the Parkinson's disease MPTP-mice [92-94].

Endogenous Nrf2 is the main regulator of the antioxidant response and an indicator of oxidative stress. Numerous research data indicated that $\mathrm{Nrf} 2$ mediated the neuroprotective effect of active ingredients of Chinese herbal medicine on Parkinson's disease [95, 96], Alzheimer's disease $[97,98]$, vascular dementia $[99,100]$, and cerebral ischemiareperfusion injury [101-103]. In vivo and in vitro studies suggested that isobavachalcone may act as a potential neuroprotective agent by increasing Nrf2 activity and expression [30,31]. The therapeutic potential of EPO in brain plays a neuroprotective role against Alzheimer's disease [104, 105], Parkinson's disease [106-108], chronic cerebral hypoperfusion-induced vascular dementia [109, 110], and cerebral ischemia-reperfusion injury [111-113]. The elevation of expression and circulating concentration of EPO improved the therapeutic effects of bavachalcone and other flavonoids of Chinese herbal medicine in brain diseases [59, 114-116]. The neuroprotective effects of psoralea prenylflavonoids are summarized in Figure 6.

\section{Improve Osteoporosis}

Senile osteoporosis is caused by aging and affects both men and women. The evidences showed that (1) senescence of bone marrow stromal cells (BMSCs) was more likely to differentiate into adipocytes rather than osteoblasts $[117,118]$; (2) age-dependent bone loss is associated with increased bone cell DNA damage, cell aging, SASP, and elevated RANKL levels [119-121]; and (3) excessive osteoclast activity induced by aging is closely related to inflammation, which 


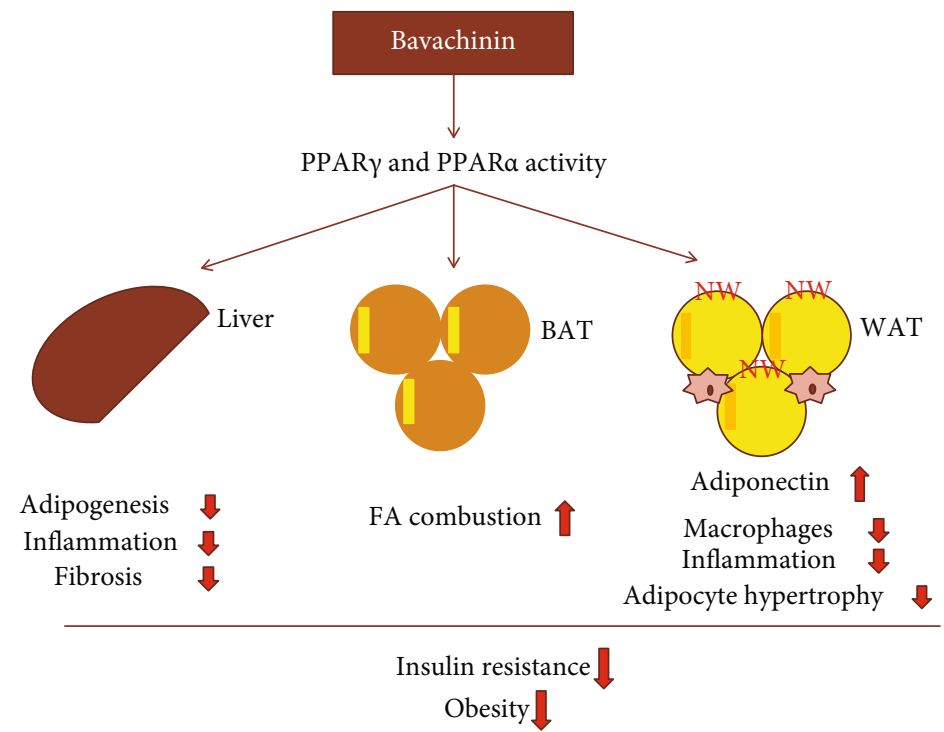

Figure 5: The schematic diagram of bavachinin activating PPARs to improve insulin resistance and obesity.

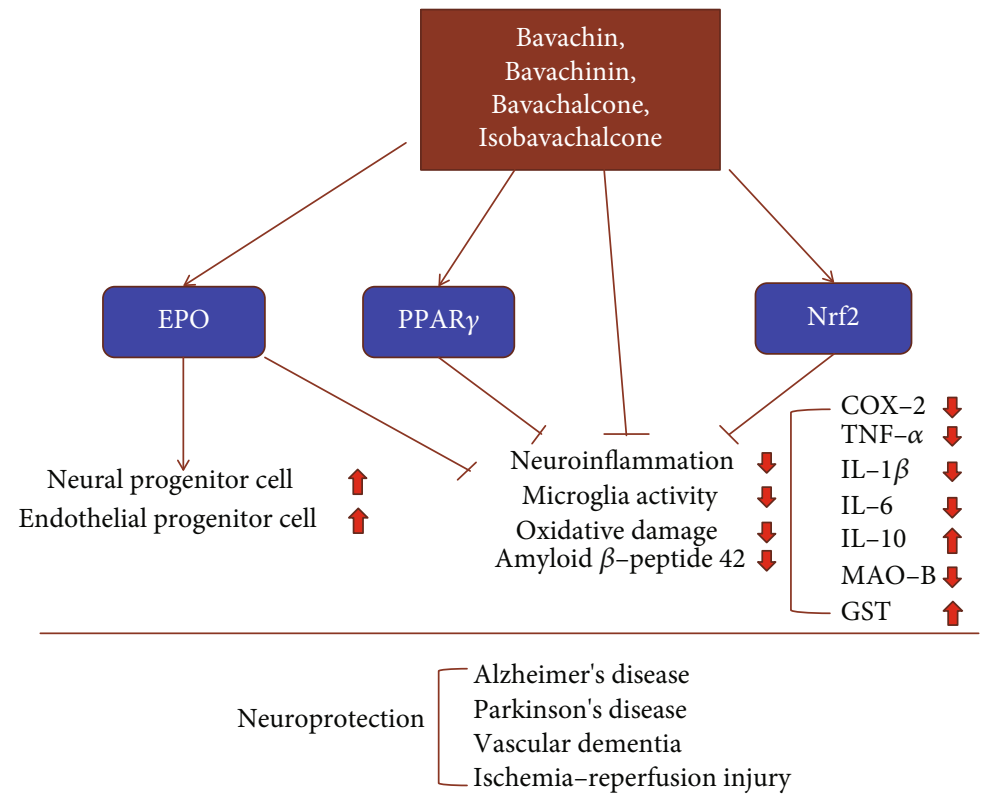

FIGURE 6: The schematic diagram of the neuroprotective effects of multiple prenylflavonoids by promoting EPO, Nrf2, PPAR $\gamma$ activation, and direct anti-inflammatory effects.

induced osteoporosis, while anti-inflammatory drugs inhibit osteoclast formation and bone resorption [122-124].

In China, fructus psoraleae is often used to treat fractures, osteomalacia, and osteoporosis. A phytoestrogen effect was considered to play an important role in studies on the material basis of fructus psoraleae and its pharmacological action (Table 2). Xin and colleagues [125] found that bavachin, isobavachalcone, and neobavaisoflavone activate estrogen receptor $\operatorname{ER} \alpha$ and $\operatorname{ER} \beta$, while pure estrogen antagonists ICI-182,780 completely block the activation of estrogen receptors. Bavachin, isobavachalcone, and neobavaisoflavone also significantly promoted osteoblast proliferation [126]. In a model of bone loss caused by ovariectomy, in vivo experi- ments showed that bavachin prevents bone loss by upregulating the Wnt signaling pathway [127]. Wnt/ $\beta$-catenin signaling pathway regulated cell fate and promoted BMSCs transfer to osteoblasts rather than adipocytes [128, 129]. Neobavaisoflavone stimulated osteogenesis of MC3T3-E1 osteoblasts in a dose-dependent manner, which is manifested by notable enhancement of ALP activity, significantly increased bone-specific matrix proteins including type I collagen (Col-I), osteocalcin (OCN), and bone sialoprotein (BSP) and formation of bone nodules. Neobavaisoflavone also upregulated the mRNA expression of transcription factors Runx2 and Osterix (Osx) through a p38-dependent signaling pathway then exerted osteogenic activity [130]. 


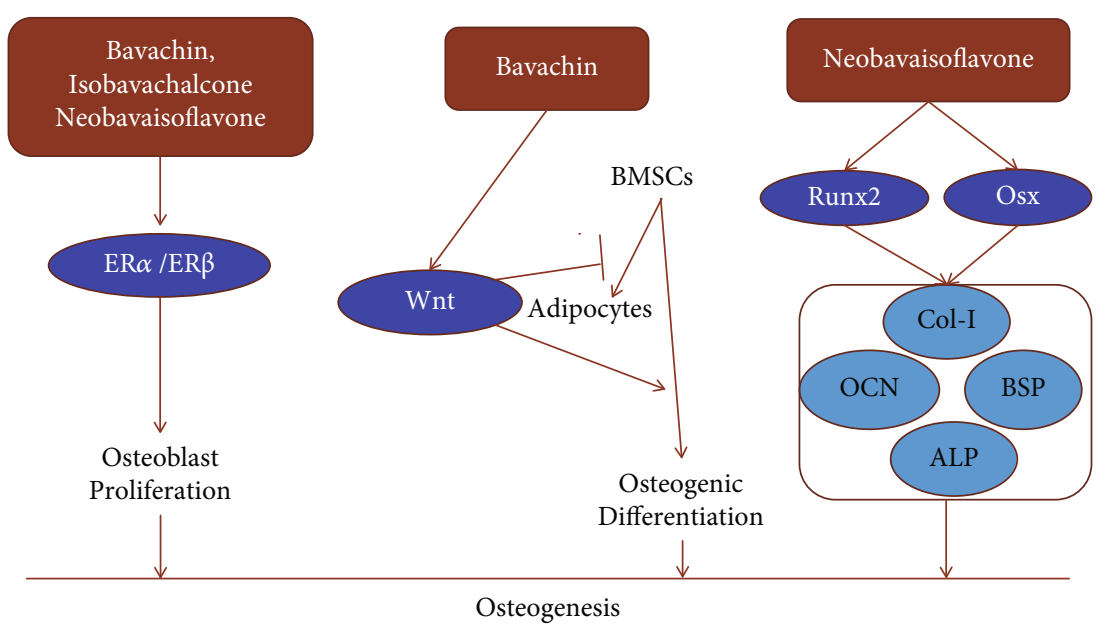

FIgURE 7: The schematic diagram of multiple prenylflavonoids promoting the differentiation of osteoblasts via regulating ER $\alpha / \beta$, Wnt, Runx2, and Osx.

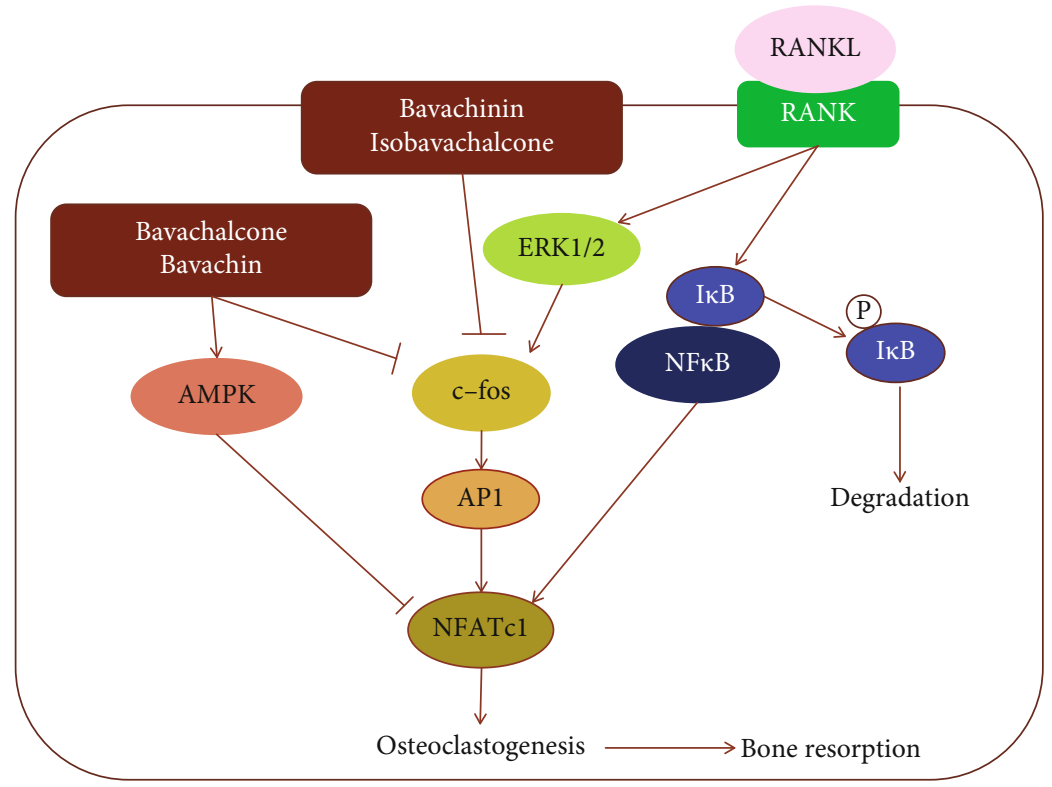

FIGURE 8: The schematic diagram of multiple prenylflavonoids inhibiting osteoclast differentiation and bone resorption induced by RANKL.

Runx2, ALP, and OCN are integral factors for the control of osteogenesis. Many research reported that Runx2 can promote osteogenic differentiation and inhibit fat differentiation $[131,132]$. As an osteoblast-specific transcription factor, Osx is also required for osteoblast differentiation. Osx showed a transcriptional regulatory mechanism for BSP gene expression, which is related to osteoblast differentiation and the onset of mineralization [133]. Interestingly, aiming at 162 potential bone-promoting target proteins, Ge et al. [134] revealed that 8 ingredients of 23 known psoralen components, such as bavachalcone, bavachinin, and neobavaisoflavone, may be the main activities of psoralea-promoting bone formation in MC3T3-E1 cells. In summary, psoralea prenylflavonoids promoted bone formation in many ways (Figure 7).

Contrary to osteoblasts, osteoclast is a kind of cell that has a special effect on bone absorption. Disorder of bone absorption is the main culprit of many bone diseases such as osteoporosis. Bavachalcone inhibited the differentiation of precursor cells into osteoclasts by interfering with the extracellular regulated protein kinases (ERK) and Akt pathways and suppressed the expression of c-Fos and NFATc1 via receptor activator of nuclear factor $\kappa \mathrm{B}$ ligand (RANKL) [135]. NFATc1 induced by the cytokine RANKL is a major regulator of the osteoclast transcriptome. NFATc1 promoted the expression of many genes, such as Itgb3, Oscar, Acp5, and Ctsk promoters, which were required for osteoclastogenesis and bone resorption [136]. NFATc1 protein expression and transcriptional activity also played important roles in inflammatory osteoclastogenesis and pathological bone loss $[137,138]$. An earlier study reported that bavachalcone can intervene with osteoclastogenesis by inhibiting the induction of c-Fos and NFATc1 [135]. AMPK, a negative regulator of 
NFATc1 activation, antagonized osteoclastogenesis [139, 140]. Estrogen and phytoestrogens also negatively regulated the RANKL-induced osteoclastic differentiation [141-143]. Many studies revealed that psoralea prenylflavonoids activate the AMPK pathway and present estrogen-like effects, which explained their inhibitory mechanism on osteoclastogenesis (Figure 8).

In conclusion, this article summarizes the numerous pharmacological effects of psoralea prenylflavonoids on aging-related diseases, including anti-inflammatory action, cardiovascular protection, diabetes and obese intervention, neurodegenerative diseases improvement, and osteoporosis alleviation. This article also discusses the regulation of these active ingredients on the key pathways, such as AMPK, EPO, HIF- $1 \alpha$, NFATc1, NF- $\kappa$ B, Nrf2, Osx, PPAR $\gamma$, Runx2, and $\mathrm{Wnt} / \beta$-catenin, as well as inflammatome NLRP3. However, there is insufficient evidence to prove that these five psoralea prenylflavonoids can be used as senolytics (eliminating senescent cells) or as senomorphics (modifying SASP components) drugs and can only be considered to prevent certain aging-related signaling pathways by entering cells. The summary and discussion of the pharmacological effects and regulatory mechanisms of psoralea prenylflavonoids will help to improve the recognition of the material basis of the pharmaceutical function of fructus psoraleae and will have a positive significance for the interpretation of its pharmacological effect.

\section{Abbreviations}

A $\beta 42:$

ACAT:

AD:

ADAMTS:

Akt:

ALP:

AMPK:

ARE:

BSP:

$\mathrm{C} / \mathrm{EBP} \alpha$ :

Col-I:

COX-2:

CTGF:

EPCs:

EPO:

ERK:

GLUT:

HFpEF:

HIF- $1 \alpha$ :

hTRPC3:

ICAM-1:

IFN- $\beta$ :

IL- $1 \alpha$ :

iNOS:

$\mathrm{I} \kappa \mathrm{B} \alpha$ :
A 42 amino acid proteolytic product from the amyloid precursor protein

Acyl-CoA:cholesterol acyltransferase

Alzheimer's disease

A disintegrin and metalloproteinase with thrombospondin motif

Protein kinase B

Alkaline phosphatase

Adenosine $5^{\prime}$-monophosphate-activated protein kinase

Antioxidant responsive element

Bone sialoprotein

CCAAT/enhancer binding protein alpha

Type I collagen

Cyclooxygenase- 2

Connective tissue growth factor

Endothelial progenitor cells

Erythropoietin

Extracellular regulated protein kinases

Glucose transport protein

Heart failure with preserved ejection fraction

Hypoxia-inducible factor 1alpha

Human transient receptor potential cation

channel subfamily $\mathrm{C}$ member 3

Intercellular adhesion molecule-1

Interferon beta

Interleukin 1 alpha

Inducible nitric oxide

NFKB inhibitor alpha
LPS: Lipopolysaccharide

MAO-B: $\quad$ Monoamine oxidase B

MCP-1: $\quad$ Monocyte chemoattractant protein-1

Medium MDI: Medium with M-CSF/dexamethasone/IL-4

MMPs: $\quad$ Matrix metalloproteinases

MnSOD: $\quad$ Manganese-superoxide dismutase

MRC1: $\quad$ Mannose receptor C-type 1

mPGES-1: $\quad$ Prostaglandin E synthase-1

MPTP: 1-Methyl-4-phenyl-1,2,3,6-

tetrahydropyridine

MyD88: $\quad$ MYD88 innate immune signal transduction adaptor

NADPH: $\quad$ Nicotinamide adenine dinucleotide phosphate

NFATc1: $\quad$ Nuclear factor of activated T cells 1

NF- $\kappa$ B: $\quad$ Nuclear factor kappa-light-chain-enhancer of activated $B$ cells

NLRP3: $\quad$ NOD-, LRR-, and pyrin domain-containing protein 3

NO: $\quad$ Nitric oxide

Nrf2: $\quad$ Nuclear factor erythroid 2-related factor 2

OCN: Osteocalcin

PD: $\quad$ Parkinson's disease

$\mathrm{PGE}_{2}$ : $\quad$ Prostaglandin E2

PKM2: $\quad$ Pyruvate kinase M2

PPAR $\gamma$ : Peroxisome proliferator-activated receptor gamma

RANKL: $\quad$ Receptor activator of nuclear factor $\kappa \mathrm{B}$ ligand

ROR $\alpha$ 1: $\quad$ Retinoid-related orphan receptor alpha1

STAT3: $\quad$ Signal transducer and activator of transcription 3

TGF- $\beta$ : $\quad$ Transforming growth factor beta

TLR4: $\quad$ Toll-like receptor 4

TNF- $\alpha$ : Tumor necrosis factor alpha

Trx1: $\quad$ Thioredoxin

TXNIP: $\quad$ Thioredoxin interacting protein

VEGF: Vascular endothelial growth factor

VHL: von Hippel-Lindau.

\section{Conflicts of Interest}

The authors declare that they have no competing interests.

\section{Authors' Contributions}

Yi-Ting Zhou and Lin Zhu contributed equally to this work.

\section{Acknowledgments}

This work was supported by grants from the Specialized Research Fund for the National Natural Science Foundation of China (81274130 and 81973511).

\section{References}

[1] T. T. Yang and M. J. Qin, "Isolation and structure identification of a new isoflavone from Psoralea corylifolias," Acta pharmaceutica Sinica, vol. 41, no. 1, pp. 76-79, 2006. 
[2] R. P. Yang, Q. Y. Shou, X. M. Zhang, B. H. Wang, and N. Li, "Chemical composition analysis of ethyl acetate extract active fractions from Psoralea corylifolia (Article in Chinese)," Chong Qing Zhong Cao Yao Yan Jiu, vol. 64, no. 2, pp. 1315, 2011.

[3] Y. F. Yang, Y. B. Zhang, Z. J. Chen, Y. T. Zhang, and X. W. Yang, "Plasma pharmacokinetics and cerebral nuclei distribution of major constituents of Psoraleae fructus in rats after oral administration," Phytomedicine, vol. 38, no. 38, pp. 166174, 2018.

[4] D. Zhou, L. An, Y. Xia, Y. Wang, and X. Li, "Quantitative bioanalysis of bavachalcone in rat plasma by LC-MS/MS and its application in a pharmacokinetics study," Biomedical Chromatography, vol. 31, no. 12, article e4031, 2017.

[5] Z. J. Li, A. Abulizi, G. L. Zhao et al., "Bakuchiol Contributes to the Hepatotoxicity of Psoralea corylifolia in Rats," Phytotherapy Research, vol. 31, no. 8, pp. 1265-1272, 2017.

[6] Y. Wang, H. Zhang, J. M. Jiang et al., "Hepatotoxicity induced by psoralen and isopsoralen from Fructus Psoraleae: Wistar rats are more vulnerable than ICR mice," Food and Chemical Toxicology, vol. 125, pp. 133-140, 2019.

[7] J. H. Choi, M. C. Rho, S. W. Lee et al., "Bavachin and isobavachalcone, acyl-coenzyme A: Cholesterol acyltransferase inhibitors from Psoralea corylifolia," Archives of Pharmacal Research, vol. 31, no. 11, pp. 1419-1423, 2008.

[8] Y. G. Li, J. Hou, S. Y. Li et al., "Fructus Psoraleae contains natural compounds with potent inhibitory effects towards human carboxylesterase 2," Fitoterapia, vol. 101, pp. 99106, 2015.

[9] L. Shan, S. Yang, G. Zhang et al., "Comparison of the Inhibitory Potential of Bavachalcone and Corylin against UDPGlucuronosyltransferases," Evidence-Based Complementary and Alternative Medicine, vol. 2014, Article ID 958937, 6 pages, 2014.

[10] X. X. Wang, X. Lv, S. Y. Li et al., "Identification and characterization of naturally occurring inhibitors against UDP-glucuronosyltransferase $1 \mathrm{~A} 1$ in Fructus Psoraleae (Bu-gu-zhi)," Toxicology and Applied Pharmacology, vol. 289, no. 1, pp. 70-78, 2015.

[11] M. Shi, Y. Cui, C. Liu, C. Li, Z. Liu, and W.-y. Kang, "CYPsmediated drug-drug interactions on psoralidin, isobavachalcone, neobavaisoflavone and daidzein in rats liver microsomes," Food and Chemical Toxicology, vol. 136, article 111027, 2020.

[12] F. Olivieri, F. Prattichizzo, J. Grillari, and C. R. Balistreri, "Cellular senescence and inflammaging in age-related diseases," Mediators of Inflammation, vol. 2018, Article ID 9076485, 6 pages, 2018.

[13] F. Gurău, S. Baldoni, F. Prattichizzo et al., "Anti-senescence compounds: a potential nutraceutical approach to healthy aging," Ageing Research Reviews, vol. 46, pp. 14-31, 2018.

[14] D. Kim, H. Li, Y. Han, J. Jeong, H. Lee, and J.-H. Ryu, "Modulation of Inducible Nitric Oxide Synthase Expression in LPS-Stimulated BV-2 Microglia by Prenylated Chalcones from Cullen corylifolium (L.) Medik. through Inhibition of I- $\kappa \mathrm{B} \alpha$ Degradation,” Molecules, vol. 23, no. 1, p. 109, 2018.

[15] M. H. Lee, J. Y. Kim, and J. H. Ryu, "Prenylflavones from Psoralea corylifolia inhibit nitric oxide synthase expression through the inhibition of I- $\kappa \mathrm{B}-\alpha$ degradation in activated microglial cells," Biological and Pharmaceutical Bulletin, vol. 28, no. 12, pp. 2253-2257, 2005.
[16] H. J. Shin, D. H. Shon, and H. S. Youn, "Isobavachalcone Suppresses Expression of Inducible Nitric Oxide Synthase Induced by Toll-like Receptor Agonists," International Immunopharmacology, vol. 15, no. 1, pp. 38-41, 2013.

[17] G. J. Lee, I. A. Cho, K. R. Kang et al., "Biological effects of the herbal plant-derived phytoestrogen Bavachin in primary rat chondrocytes," Biological and Pharmaceutical Bulletin, vol. 38, no. 8, pp. 1199-1207, 2015.

[18] Y.-L. Hung, S.-C. Wang, K. Suzuki et al., "Bavachin attenuates LPS-induced inflammatory response and inhibits the activation of NLRP3 inflammasome in macrophages," Phytomedicine, vol. 59, article 152785, 2019.

[19] C. C. Cheng, Y. H. Chen, W. L. Chang et al., "Phytoestrogen bavachin mediates anti-inflammation targeting $\mathrm{I} \kappa \mathrm{B}$ kinase$\mathrm{I} \kappa \mathrm{B} \alpha-\mathrm{NF}-\kappa \mathrm{B}$ signaling pathway in chondrocytes in vitro," European Journal of Pharmacology, vol. 636, no. 1-3, pp. 181-188, 2010.

[20] K. M. Lee, J. M. Kim, E. J. Baik, J. H. Ryu, and S. H. Lee, “Isobavachalcone attenuates lipopolysaccharide-induced ICAM1 expression in brain endothelial cells through blockade of toll-like receptor 4 signaling pathways," European Journal of Pharmacology, vol. 754, pp. 11-18, 2015.

[21] E. Szliszka, D. Skaba, Z. P. Czuba, and W. Krol, "Inhibition of inflammatory mediators by neobavaisoflavone in activated RAW264.7 macrophages," Molecules, vol. 16, no. 5, pp. 3701-3712, 2011.

[22] S. W. Lee, B. R. Yun, M. H. Kim et al., "Phenolic compounds isolated from Psoralea corylifolia inhibit IL-6-induced STAT3 activation," Planta Medica, vol. 78, no. 9, pp. 903906, 2012.

[23] M. Nepal, H. J. Choi, B.-Y. Choi et al., “Anti-angiogenic and anti-tumor activity of Bavachinin by targeting hypoxiainducible factor- $1 \alpha$," European Journal of Pharmacology, vol. 691, no. 1-3, pp. 28-37, 2012.

[24] S. Rey and G. L. Semenza, "Hypoxia-inducible factor-1dependent mechanisms of vascularization and vascular remodelling," Cardiovascular Research, vol. 86, no. 2, pp. 236-242, 2010.

[25] G. M. Tannahill, A. M. Curtis, J. Adamik et al., "Succinate is an inflammatory signal that induces IL- $1 \beta$ through HIF- $1 \alpha$," Nature, vol. 496, no. 7444, pp. 238-242, 2013.

[26] A. Palazon, A. W. Goldrath, V. Nizet, and R. S. Johnson, "HIF Transcription Factors, Inflammation, and Immunity," Immunity, vol. 41, no. 4, pp. 518-528, 2014.

[27] C. T. Taylor and S. P. Colgan, "Regulation of immunity and inflammation by hypoxia in immunological niches," Nature Reviews Immunology, vol. 17, no. 12, pp. 774-785, 2017.

[28] E. M. Palsson-McDermott, A. M. Curtis, G. Goel et al., "Pyruvate Kinase M2 Regulates Hif- $1 \alpha$ Activity and IL- $1 \beta$ Induction and Is a Critical Determinant of the Warburg Effect in LPS-Activated Macrophages," Cell Metabolism, vol. 21, no. 1, pp. 65-80, 2015.

[29] I. Warbrick and S. W. Rabkin, "Hypoxia-inducible factor 1-alpha $(\mathrm{HIF}-1 \alpha)$ as a factor mediating the relationship between obesity and heart failure with preserved ejection fraction," Obesity Reviews, vol. 20, no. 5, pp. 701-712, 2019.

[30] D. Gao, F. Liu, Z. Li, and Y. Guan, "Isobavachalcone attenuates Sephadex-induced lung injury via activation of A20 and NRF2/HO-1 in rats," European Journal of Pharmacology, vol. 848, pp. 49-54, 2019. 
[31] J. Hur, M. Kim, S. Y. Choi, Y. Jang, and T. Y. Ha, "Isobavachalcone attenuates myotube atrophy induced by TNF- $\alpha$ through muscle atrophy F-box signaling and the nuclear factor erythroid 2-related factor 2 cascade," Phytotherapy Research, vol. 33, no. 2, pp. 403-411, 2019.

[32] E. H. Kobayashi, T. Suzuki, R. Funayama et al., "Nrf2 suppresses macrophage inflammatory response by blocking proinflammatory cytokine transcription," Nature Communications, vol. 7, no. 1, article 11624, 2016.

[33] C. J. Schmidlin, M. B. Dodson, L. Madhavan, and D. D. Zhang, "Redox regulation by NRF2 in aging and disease," Free Radical Biology \& Medicine, vol. 134, pp. 702-707, 2019.

[34] D. R. Bruns, J. C. Drake, L. M. Biela, F. F. Peelor, B. F. Miller, and K. L. Hamilton, "Nrf2 signaling and the slowed aging phenotype: evidence from long-lived models," Oxidative Medicine and Cellular Longevity, vol. 2015, 15 pages, 2015.

[35] A. M. Kuhn, N. Tzieply, M. V. Schmidt et al., "Antioxidant signaling via Nrf2 counteracts lipopolysaccharide-mediated inflammatory responses in foam cell macrophages," Free Radical Biology and Medicine, vol. 50, no. 10, pp. 13821391, 2011.

[36] A. Silva-Palacios, M. Königsberg, and C. Zazueta, "Nrf2 signaling and redox homeostasis in the aging heart: a potential target to prevent cardiovascular diseases?," Ageing Research Reviews, vol. 26, pp. 81-95, 2016.

[37] L. Fão, S. I. Mota, and A. C. Rego, "Shaping the Nrf2-ARErelated pathways in Alzheimer's and Parkinson's diseases," Ageing Research Reviews, vol. 54, article 100942, 2019.

[38] M. L. Ferrándiz, J. Nacher-Juan, and M. J. Alcaraz, "Nrf2 as a therapeutic target for rheumatic diseases," Biochemical Pharmacology, vol. 152, pp. 338-346, 2018.

[39] X. Liu, X. Zhang, Y. Ding et al., "Nuclear factor E2-related factor-2 negatively regulates NLRP3 inflammasome activity by inhibiting reactive oxygen species-induced NLRP3 priming," Antioxidants \& Redox Signaling, vol. 26, no. 1, pp. 2843, 2017.

[40] Y. Hou, Y. Wang, Q. He et al., "Nrf2 inhibits NLRP3 inflammasome activation through regulating Trx1/TXNIP complex in cerebral ischemia reperfusion injury," Behavioural Brain Research, vol. 336, pp. 32-39, 2018.

[41] R. Venugopal and A. K. Jaiswal, "Nrf1 and Nrf2 positively and c-Fos and Fral negatively regulate the human antioxidant response element-mediated expression of NAD $(\mathrm{P}) \mathrm{H}:-$ quinone oxidoreductasel gene," Proceedings of the National Academy of Sciences of the United States of America, vol. 93, no. 25, pp. 14960-14965, 1996.

[42] Y. Yuan, S. Ling, and J. W. Xu, "4'-O-methybavachalcone protects ischemic stroke through inhibiting pyroptosis by targeting NLRP3/GSDMD axis in mice," In preparation.

[43] D. Zhang, J. Qian, P. Zhang et al., "Gasdermin D serves as a key executioner of pyroptosis in experimental cerebral ischemia and reperfusion model both in vivo and in vitro," Journal of Neuroscience Research, vol. 97, no. 6, pp. 645-660, 2019.

[44] J. Li, J. H. Hao, D. Yao et al., "Caspase-1 inhibition prevents neuronal death by targeting the canonical inflammasome pathway of pyroptosis in a murine model of cerebral ischemia," CNS Neuroscience \& Therapeutics, 2020.

[45] H. Lee, H. Li, M. Noh, and J. H. Ryu, "Bavachin from Psoralea corylifolia improves insulin-dependent glucose uptake through insulin signaling and AMPK activation in 3T3-L1 adipocytes," International Journal of Molecular Sciences, vol. 17, no. 4, 2016.

[46] A. Croasdell, P. F. Duffney, N. Kim, S. H. Lacy, P. J. Sime, and R. P. Phipps, "PPAR $\gamma$ and the Innate Immune System Mediate the Resolution of Inflammation," PPAR Research, vol. 2015, 20 pages, 2015.

[47] T. M. De Silva, Y. Li, D. A. Kinzenbaw, C. D. Sigmund, and F. M. Faraci, "Endothelial PPAR $\gamma$ (peroxisome proliferatoractivated receptor- $\gamma$ ) is essential for preventing endothelial dysfunction with aging," Hypertension, vol. 72, no. 1, pp. 227-234, 2018.

[48] M. L. Modrick, D. A. Kinzenbaw, Y. Chu, C. D. Sigmund, and F. M. Faraci, "Peroxisome proliferator-activated receptor- $\gamma$ protects against vascular aging," American Journal of Physiology-Regulatory, Integrative and Comparative Physiology, vol. 302, no. 10, pp. R1184-R1190, 2012.

[49] S. Lim, K.-S. Lee, J. E. Lee et al., "Effect of a new PPARgamma agonist, lobeglitazone, on neointimal formation after balloon injury in rats and the development of atherosclerosis," Atherosclerosis, vol. 243, no. 1, pp. 107-119, 2015.

[50] A. Briot, P. Decaunes, F. Volat et al., "Senescence alters PPAR $\gamma$ (peroxisome proliferator-activated receptor gamma)-dependent fatty acid handling in human adipose tissue microvascular endothelial cells and favors inflammation," Arteriosclerosis, Thrombosis, and Vascular Biology, vol. 38, no. 5, pp. 1134-1146, 2018.

[51] A. K. Gebremeskel, T. D. Wijerathne, J. H. Kim et al., "Psoralea corylifolia extract induces vasodilation in rat arteries through both endothelium-dependent and -independent mechanisms involving inhibition of TRPC3 channel activity and elaboration of prostaglandin," Pharmaceutical Biology, vol. 55, no. 1, pp. 2136-2144, 2016.

[52] W. J. Tsai, W. C. Hsin, and C. C. Chen, "Antiplatelet Flavonoids from Seeds of Psoralea corylifolia," Journal of Natural Products, vol. 59, no. 7, pp. 671-672, 1996.

[53] M. Bhatti, S. Ayton, O. Michail et al., "Effect of Bruton's tyrosine kinase inhibitors on platelet aggregation in patients with acute myocardial infarction," Thrombosis Research, vol. 179, pp. 64-68.

[54] L. Yang, X. Chen, S. Wang et al., "N2 extenuates experimental ischemic stroke through platelet aggregation inhibition," Thrombosis Research, vol. 136, no. 6, pp. 1310-1317, 2015.

[55] X. H. Yu, Y. C. Fu, D. W. Zhang, K. Yin, and C. K. Tang, "Foam cells in atherosclerosis," Clinica Chimica Acta, vol. 424, pp. 245-252, 2013.

[56] M. A. Rogers, J. Liu, B.-L. Song, B.-L. Li, C. C. Y. Chang, and T.-Y. Chang, "Acyl-CoA:cholesterol acyltransferases (ACATs/SOATs): enzymes with multiple sterols as substrates and as activators," The Journal of Steroid Biochemistry and Molecular Biology, vol. 151, pp. 102-107, 2015.

[57] Y. Dang, S. Ling, J. Ma, R. Ni, and J.-W. Xu, "Bavachalcone enhances ROR $\alpha$ expression, controls Bmall circadian transcription, and depresses cellular senescence in human endothelial cells," Evidence-based Complementary and Alternative Medicine, vol. 2015, Article ID 920431, 11 pages, 2015.

[58] Y. Dang, S. Ling, J. Duan, J. Ma, R. Ni, and J. W. Xu, “Bavachalcone-induced manganese superoxide dismutase expression through the AMP-activated protein kinase pathway in human endothelial cells," Pharmacology, vol. 95, no. 3-4, pp. 105-110, 2015. 
[59] S. Ling, R. Z. Ni, Y. Yuan et al., "Natural compound bavachalcone promotes the differentiation of endothelial progenitor cells and neovascularization through the ROR $\alpha$-erythropoietin-AMPK axis," Oncotarget, vol. 8, no. 49, pp. 86188-86205, 2017.

[60] F. H. Bahlmann, K. de Groot, J.-M. Spandau et al., "Erythropoietin regulates endothelial progenitor cells," Blood, vol. 103, no. 3, pp. 921-926, 2004.

[61] M. Ferrario, M. Massa, V. Rosti et al., "Early haemoglobinindependent increase of plasma erythropoietin levels in patients with acute myocardial infarction," European Heart Journal, vol. 28, no. 15, pp. 1805-1813, 2007.

[62] M. Hoch, P. Fischer, B. Stapel et al., "Erythropoietin preserves the endothelial differentiation capacity of cardiac progenitor cells and reduces heart failure during anticancer therapies," Cell Stem Cell, vol. 9, no. 2, pp. 131-143, 2011.

[63] L. Wang, X. Wang, H. Su et al., "Recombinant human erythropoietin improves the neurofunctional recovery of rats following traumatic brain injury via an increase in circulating endothelial progenitor cells," Translational Stroke Research, vol. 6, no. 1, pp. 50-59, 2015.

[64] Y. Xu, Y. Tian, H. J. Wei et al., "Erythropoietin increases circulating endothelial progenitor cells and reduces the formation and progression of cerebral aneurysm in rats," Neuroscience, vol. 181, pp. 292-299, 2011.

[65] D. Kukidome, T. Nishikawa, K. Sonoda et al., "Activation of AMP-Activated Protein Kinase Reduces HyperglycemiaInduced Mitochondrial Reactive Oxygen Species Production and Promotes Mitochondrial Biogenesis in Human Umbilical Vein Endothelial Cells," Diabetes, vol. 55, no. 1, pp. 120-127, 2005.

[66] S. Kröller-Schön, T. Jansen, F. Hauptmann et al., “ $\alpha 1$ AMPActivated protein kinase mediates vascular protective effects of exercise," Arteriosclerosis, Thrombosis, and Vascular Biology, vol. 32, no. 7, pp. 1632-1641, 2012.

[67] Z. Chen, I. C. Peng, W. Sun et al., "AMP-Activated protein kinase functionally phosphorylates endothelial nitric oxide synthase Ser633," Circulation Research, vol. 104, no. 4, pp. 496-505, 2009.

[68] J. Brandauer, M. A. Andersen, H. Kellezi et al., "AMP-activated protein kinase controls exercise training- and AICAR-induced increases in SIRT3 and MnSOD," Frontiers in Physiology, vol. 6, 2015.

[69] X. Li, Y. Han, W. Pang et al., "AMP-activated protein kinase promotes the differentiation of endothelial progenitor cells," Arteriosclerosis, Thrombosis, and Vascular Biology, vol. 28, no. 10, pp. 1789-1795, 2008.

[70] V. M. Mendoza-Núñez, J. Rosado-Pérez, E. Santiago-Osorio, R. Ortiz, M. A. Sánchez-Rodríguez, and R. E. Galván-Duarte, "Aging linked to type 2 diabetes increases oxidative stress and chronic inflammation," Rejuvenation Researcher, vol. 14, no. 1, pp. 25-31, 2011.

[71] M. K. Figaro, S. B. Kritchevsky, H. E. Resnick et al., "Diabetes, Inflammation, and Functional Decline in Older Adults: Findings from the Health, Aging and Body Composition (ABC) study," Diabetes Care, vol. 29, no. 9, pp. 2039-2045, 2006.

[72] Y. Hasegawa, T. Saito, T. Ogihara et al., "Blockade of the nuclear factor- $\kappa \mathrm{B}$ pathway in the endothelium prevents insulin resistance and prolongs life spans," Circulation, vol. 125, no. 9, pp. 1122-1133, 2012.
[73] L. C. Bailey-Downs, Z. Tucsek, P. Toth et al., "Aging Exacerbates Obesity-Induced Oxidative Stress and Inflammation in Perivascular Adipose Tissue in Mice: A Paracrine Mechanism Contributing to Vascular Redox Dysregulation and Inflammation," The Journals of Gerontology. Series A, Biological Sciences and Medical Sciences, vol. 68, no. 7, pp. 780-792, 2013.

[74] J. Liu, Y. Zhao, C. Huang, Y. Li, and F. Guo, "Prenylated flavonoid-standardized extract from seeds of Psoralea corylifolia L. activated fat browning in high-fat diet-induced obese mice," Phytotherapy Research, vol. 33, no. 7, pp. 1851-1864, 2019.

[75] C. S. Truong, E. Seo, and H. S. Jun, "Psoralea corylifolia L. Seed Extract Attenuates Methylglyoxal-Induced Insulin Resistance by Inhibition of Advanced Glycation End Product Formation," Oxidative Medicine and Cellular Longevity, vol. 2019, Article ID 4310319, 14 pages, 2019.

[76] E. Seo, Y. S. Oh, and H. S. Jun, "Psoralea corylifolia L. Seed Extract Attenuates Nonalcoholic Fatty Liver Disease in High-Fat Diet-Induced Obese Mice," Nutrients, vol. 8, no. 2 , p. 83, 2016.

[77] C. B. Shrikanth and C. D. Nandini, "AMPK in microvascular complications of diabetes and the beneficial effects of AMPK activators from plants," Phytomedicine, vol. 73, 2020.

[78] T. Joshi, A. K. Singh, P. Haratipour et al., "Targeting AMPK signaling pathway by natural products for treatment of diabetes mellitus and its complications," Journal of Cellular Physiology, vol. 234, no. 10, pp. 17212-17231, 2019.

[79] G. Du, L. Feng, Z. Yang et al., "Separation and peroxisome proliferator-activated receptor- $\gamma$ agonist activity evaluation of synthetic racemic bavachinin enantiomers," Bioorganic \& Medicinal Chemistry Letters, vol. 25, no. 12, pp. 2579-2583, 2015.

[80] L. Feng, H. Luo, Z. Xu et al., "Bavachinin, as a novel natural pan-PPAR agonist, exhibits unique synergistic effects with synthetic PPAR- $\gamma$ and PPAR- $\alpha$ agonists on carbohydrate and lipid metabolism in $\mathrm{db} / \mathrm{db}$ and diet-induced obese mice," Diabetologia, vol. 59, no. 6, pp. 1276-1286, 2016.

[81] H. Lee, H. Li, M. Kweon, Y. Choi, M. Kim, and J.-H. Ryu, "Isobavachalcone from Angelica keiskei inhibits adipogenesis and prevents lipid accumulation," International Journal of Molecular Sciences, vol. 19, no. 6, 2018.

[82] Q. X. Xu, Y. Hu, G. Y. Li, W. Xu, Y. T. Zhang, and X. W. Yang, "Multi-target anti-Alzheimer activities of four prenylated compounds from Psoralea fructus," Molecules, vol. 23, no. 3, 2018.

[83] X. Chen, Y. Yang, and Y. Zhang, "Isobavachalcone and bavachinin fromPsoraleae Fructusmodulate A $\beta 42$ aggregation process through different mechanisms in vitro," FEBS Letters, vol. 587, no. 18, pp. 2930-2935, 2013.

[84] H. Jing, S. Wang, M. Wang, W. Fu, C. Zhang, and D. Xu, "Isobavachalcone attenuates MPTP-induced Parkinson's disease in mice by inhibition of microglial activation through NF- $\kappa$ B pathway," PLoS One, vol. 12, no. 1, article e0169560, 2017.

[85] Y. Kim, H.-S. Lim, J. Lee, and S.-J. Jeong, "Quantitative analysis of Psoralea corylifolia Linne and its neuroprotective and anti-neuroinflammatory effects in HT22 hippocampal cells and BV-2 microglia," Molecules, vol. 21, no. 8, 2016.

[86] N. O. Zarmouh, E. A. Mazzio, F. M. Elshami, S. S. Messeha, S. V. K. Eyunni, and K. F. A. Soliman, "Evaluation of the inhibitory effects of bavachinin and bavachin on human monoamine oxidases A and B," Evidence-based Complementary 
and Alternative Medicine, vol. 2015, Article ID 852194, 14 pages, 2015.

[87] Y. Luo, W. Yin, A. P. Signore et al., "Neuroprotection against focal ischemic brain injury by the peroxisome proliferatoractivated receptor- $\gamma$ agonist rosiglitazone," Journal of Neurochemistry, vol. 97, no. 2, pp. 435-448, 2006.

[88] Z. Ou, X. Zhao, L. A. Labiche et al., "Neuronal expression of peroxisome proliferator-activated receptor-gamma (PPAR $\gamma$ ) and 15d-prostaglandin $\mathrm{J}_{2}$-Mediated protection of brain after experimental cerebral ischemia in rat," Brain Research, vol. 1096, no. 1, pp. 196-203, 2006.

[89] C. K. Combs, D. E. Johnson, J. C. Karlo, S. B. Cannady, and G. E. Landreth, "Inflammatory mechanisms in Alzheimer's disease: inhibition of $\beta$-amyloid-stimulated proinflammatory responses and neurotoxicity by PPAR $\gamma$ agonists," Journal of Neuroscience, vol. 20, no. 2, pp. 558-567, 2000.

[90] A. Badhwar, R. Brown, D. B. Stanimirovic, A. S. Haqqani, and E. Hamel, "Proteomic differences in brain vessels of Alzheimer's disease mice: normalization by PPAR $\gamma$ agonist pioglitazone," Journal of Cerebral Blood Flow \& Metabolism, vol. 37, no. 3, pp. 1120-1136, 2017.

[91] K. L. Chang, L. R. Wong, H. N. Pee, S. Yang, and P. C.-L. Ho, "Reverting metabolic dysfunction in cortex and cerebellum of APP/PS1 mice, a model for Alzheimer's disease by pioglitazone, a peroxisome proliferator-activated receptor gamma (PPAR $\gamma$ ) agonist," Molecular Neurobiology, vol. 56, no. 11, pp. 7267-7283, 2019.

[92] L. P. Quinn, B. Crook, M. E. Hows et al., "The PPAR $\gamma$ agonist pioglitazone is effective in the MPTP mouse model of Parkinson's disease through inhibition of monoamine oxidase B," British Journal of Pharmacology, vol. 154, no. 1, pp. 226233, 2008.

[93] H. L. Martin, R. B. Mounsey, S. Mustafa, K. Sathe, and P. Teismann, "Pharmacological manipulation of peroxisome proliferator-activated receptor $\gamma(\operatorname{PPAR} \gamma)$ reveals a role for anti-oxidant protection in a model of Parkinson's disease," Experimental Neurology, vol. 235, no. 2, pp. 528-538, 2012.

[94] D. Lecca, E. Janda, G. Mulas et al., "Boosting phagocytosis and anti-inflammatory phenotype in microglia mediates neuroprotection by PPAR $\gamma$ agonist MDG548 in Parkinson's disease models," British Journal of Pharmacology, vol. 175, no. 16, pp. 3298-3314, 2018.

[95] K. Trinh, L. Andrews, J. Krause et al., "Decaffeinated coffee and nicotine-free tobacco provide neuroprotection in Drosophila models of Parkinson's disease through an NRF2dependent mechanism," Journal of Neuroscience, vol. 30, no. 16, pp. 5525-5532, 2010.

[96] P. C. Chen, M. R. Vargas, A. K. Pani et al., "Nrf2-mediated neuroprotection in the MPTP mouse model of Parkinson's disease: critical role for the astrocyte," Proceedings of the National Academy of Sciences of the United States of America, vol. 106, no. 8, pp. 2933-2938, 2009.

[97] S. Li, X. Zhao, P. Lazarovici, and W. Zheng, "Artemether activation of AMPK/GSK3 $\beta$ (ser9)/Nrf2 signaling confers neuroprotection towards $\beta$-amyloid-induced neurotoxicity in $3 \mathrm{xTg}$ Alzheimer's mouse model," Oxidative Medicine and Cellular Longevity, vol. 2019, 24 pages, 2019.

[98] F. Morroni, G. Sita, A. Graziosi et al., "Neuroprotective effect of caffeic acid phenethyl ester in a mouse model of Alzheimer's disease involves Nrf2/HO-1 pathway," Aging and Disease, vol. 9, no. 4, pp. 605-622, 2018.
[99] P. Jiang, L. Chen, J. Sun et al., "Chotosan ameliorates cognitive impairment and hippocampus neuronal loss in experimental vascular dementia via activating the Nrf2-mediated antioxidant pathway," Journal of Pharmacological Sciences, vol. 139, no. 2, pp. 105-111, 2019.

[100] D.-d. Liu, X. Yuan, S.-f. Chu et al., "CZ-7, a new derivative of Claulansine $\mathrm{F}$, ameliorates 2VO-induced vascular dementia in rats through a Nrf2-mediated antioxidant responses," Acta Pharmacologica Sinica, vol. 40, no. 4, pp. 425-440, 2019.

[101] Z. Wen, W. Hou, W. Wu et al., "6-O-Galloylpaeoniflorin Attenuates Cerebral Ischemia Reperfusion-Induced Neuroinflammation and Oxidative Stress via PI3K/Akt/Nrf2 Activation," Oxidative Medicine and Cellular Longevity, vol. 2018, 14 pages, 2018.

[102] K. Gao, M. Liu, Y. Ding et al., "A phenolic amide (LyA) isolated from the fruits of Lycium barbarum protects against cerebral ischemia-reperfusion injury via $\mathrm{PKC} / \mathrm{Nrf} 2 / \mathrm{HO}-1$ pathway," Aging (Albany NY), vol. 11, no. 24, pp. 1236112374, 2019.

[103] B. Peng, P. Zhao, Y. P. Lu et al., "Z-ligustilide activates the Nrf2/HO-1 pathway and protects against cerebral ischemiareperfusion injury in vivo and in vitro," Brain Research, vol. 1520, pp. 168-177, 2013.

[104] S. T. Lee, K. Chu, J. E. Park et al., "Erythropoietin improves memory function with reducing endothelial dysfunction and amyloid-beta burden in Alzheimer's disease models," Journal of Neurochemistry, vol. 120, no. 1, pp. 115-124, 2012.

[105] M. Armand-Ugón, E. Aso, J. Moreno et al., "Memory improvement in the $\mathrm{A} \beta \mathrm{PP} / \mathrm{PS} 1$ mouse model of familial Alzheimer's disease induced by carbamylated-erythropoietin is accompanied by modulation of synaptic genes," Journal of Alzheimer's Disease, vol. 45, no. 2, pp. 407-421, 2015.

[106] N. M. Kanaan, T. J. Collier, D. M. Marchionini, S. O. McGuire, M. F. Fleming, and C. E. Sortwell, "Exogenous erythropoietin provides neuroprotection of grafted dopamine neurons in a rodent model of Parkinson's disease," Brain Research, vol. 1068, no. 1, pp. 221-229, 2006.

[107] Y. Q. Xue, L. R. Zhao, W. P. Guo, and W. M. Duan, "Intrastriatal administration of erythropoietin protects dopaminergic neurons and improves neurobehavioral outcome in a rat model of Parkinson's disease," Neuroscience, vol. 146, no. 3, pp. 1245-1258, 2007.

[108] Q.-H. Zhou, E. K.-W. Hui, J. Z. Lu, R. J. Boado, and W. M. Pardridge, "Brain penetrating IgG-erythropoietin fusion protein is neuroprotective following intravenous treatment in Parkinson's disease in the mouse," Brain Research, vol. 1382, pp. 315-320, 2011.

[109] S. Ma, J. Chen, C. Chen et al., "Erythropoietin rescues memory impairment in a rat model of chronic cerebral hypoperfusion via the EPO-R/JAK2/STAT5/PI3K/Akt/GSK-3 $\beta$ pathway," Molecular Neurobiology, vol. 55, no. 4, pp. 3290-3299, 2018.

[110] P. H. Hung, C. C. Yeh, F. C. Sung et al., "Erythropoietin prevents dementia in hemodialysis patients: a nationwide population-based study," Aging (Albany NY), vol. 11, no. 17, pp. 6941-6950, 2019.

[111] A. K. Junk, A. Mammis, S. I. Savitz et al., "Erythropoietin administration protects retinal neurons from acute ischemia-reperfusion injury," Proceedings of the National Academy of Sciences of the United States of America, vol. 99, no. 16, pp. 10659-10664, 2002. 
[112] K. Prass, A. Scharff, K. Ruscher et al., "Hypoxia-induced stroke tolerance in the mouse is mediated by erythropoietin," Stroke, vol. 34, no. 8, pp. 1981-1986, 2003.

[113] K. Liu, T. Sun, P. Wang, Y. H. Liu, L. W. Zhang, and Y. X. Xue, "Effects of erythropoietin on blood-brain barrier tight junctions in ischemia-reperfusion rats," Journal of Molecular Neuroscience, vol. 49, no. 2, pp. 369-379, 2013.

[114] K. Y. Z. Zheng, R. C. Y. Choi, A. W. H. Cheung et al., "Flavonoids from Radix Astragali induce the expression of erythropoietin in cultured cells: a signaling mediated via the accumulation of hypoxia-inducible factor- $1 \alpha$," Journal of Agricultural and Food Chemistry, vol. 59, no. 5, pp. 16971704, 2011.

[115] X. M. Wu, Z. M. Qian, L. Zhu et al., "Neuroprotective effect of ligustilide against ischaemia-reperfusion injury via upregulation of erythropoietin and down-regulation of RTP801," British Journal of Pharmacology, vol. 164, no. 2, pp. 332-343, 2011.

[116] Y. Y. Sun, S. H. Lin, H. C. Lin et al., "Cell type-specific dependency on the PI3K/Akt signaling pathway for the endogenous Epo and VEGF induction by baicalein in neurons versus astrocytes," PLoS One, vol. 8, no. 7, article e69019, 2013.

[117] Y. Kodama, Y. Takeuchi, M. Suzawa et al., "Reduced expression of interleukin-11 in bone marrow stromal cells of senescence-accelerated mice (SAMP6): relationship to osteopenia with enhanced adipogenesis," Journal of Bone and Mineral Research, vol. 13, no. 9, pp. 1370-1377, 1998.

[118] J. O. Nehlin, A. Jafari, M. Tencerova, and M. Kassem, “Aging and lineage allocation changes of bone marrow skeletal (stromal) stem cells," Bone, vol. 123, pp. 265-273, 2019.

[119] J. N. Farr, D. G. Fraser, H. Wang et al., "Identification of senescent cells in the bone microenvironment," Journal of Bone and Mineral Research, vol. 31, no. 11, pp. 1920-1929, 2016.

[120] J. N. Farr, M. Xu, M. M. Weivoda et al., “Targeting cellular senescence prevents age-related bone loss in mice," Nature Medicine, vol. 23, no. 9, pp. 1072-1079, 2017.

[121] M. Piemontese, M. Almeida, A. G. Robling et al., "Old age causes de novo intracortical bone remodeling and porosity in mice," JCI Insight, vol. 2, no. 17, 2017.

[122] X. Sun, B. Zhang, X. Pan et al., "Octyl itaconate inhibits osteoclastogenesis by suppressing $\mathrm{Hrdl}$ and activating Nrf2 signaling," The FASEB Journal, vol. 33, no. 11, pp. 12929-12940, 2019.

[123] W. Yin, S. Liu, M. Dong et al., "A new NLRP3 inflammasome inhibitor, dioscin, promotes osteogenesis," Small, vol. 16, no. 1, article e1905977, 2020.

[124] H. S. Son, J. Lee, H. I. Lee et al., "Benzydamine inhibits osteoclast differentiation and bone resorption via downregulation of interleukin-1 $\beta$ expression," Acta Pharmaceutica Sinica B, vol. 10, no. 3, pp. 462-474, 2020.

[125] D. Xin, H. Wang, J. Yang et al., "Phytoestrogens from Psoralea corylifolia reveal estrogen receptor-subtype selectivity," Phytomedicine, vol. 17, no. 2, pp. 126-131, 2010.

[126] W. D. Li, C. P. Yan, Y. Wu et al., "Osteoblasts proliferation and differentiation stimulating activities of the main components of Fructus_Psoraleae corylifoliae_, Phytomedicine, vol. 21, no. 4, pp. 400-405, 2014.

[127] Z. B. Weng, Q. Q. Gao, F. Wang et al., "Positive skeletal effect of two ingredients of Psoralea corylifolia L. on estrogen deficiency-induced osteoporosis and the possible mecha- nisms of action," Molecular and Cellular Endocrinology, vol. 417, pp. 103-113, 2015.

[128] L. Song, M. Liu, N. Ono, F. R. Bringhurst, H. M. Kronenberg, and J. Guo, "Loss of wnt/ $\beta$-catenin signaling causes cell fate shift of preosteoblasts from osteoblasts to adipocytes," Journal of Bone and Mineral Research, vol. 27, no. 11, pp. 23442358, 2012.

[129] C. N. Bennett, K. A. Longo, W. S. Wright et al., "Regulation of osteoblastogenesis and bone mass by Wnt10b," Proceedings of the National Academy of Sciences of the United States of America, vol. 102, no. 9, pp. 3324-3329, 2005.

[130] M. J. Don, L. C. Lin, and W. F. Chiou, "Neobavaisoflavone stimulates osteogenesis_via_ p38-mediated up-regulation of transcription factors and osteoid genes expression in MC3T3-E1 cells," Phytomedicine, vol. 19, no. 6, pp. 551$561,2012$.

[131] C. A. de Frutos, R. Dacquin, S. Vega, P. Jurdic, I. MachucaGayet, and M. Angela Nieto, "Snaill controls bone mass by regulating Runx2 and VDR expression during osteoblast differentiation," The EMBO Journal, vol. 28, no. 6, pp. 686-696, 2009.

[132] I. Tosa, D. Yamada, M. Yasumatsu et al., "Postnatal Runx2 deletion leads to low bone mass and adipocyte accumulation in mice bone tissues," Biochemical and Biophysical Research Communications, vol. 516, no. 4, pp. 1229-1233, 2019.

[133] Y. Yang, Y. Huang, L. Zhang, and C. Zhang, “Transcriptional regulation of bone sialoprotein gene expression by Osx," Biochemical and Biophysical Research Communications, vol. 476, no. 4, pp. 574-579, 2016.

[134] L. Ge, K. Cheng, and J. Han, "A network pharmacology approach for uncovering the osteogenic mechanisms of Psoralea corylifolia Linn," Evidence-based Complementary and Alternative Medicine, vol. 2019, 10 pages, 2019.

[135] C. K. Park, Y. Lee, E. J. Chang et al., "Bavachalcone inhibits osteoclast differentiation through suppression of NFATc1 induction by RANKL," Biochemical Pharmacology, vol. 75, no. 11, pp. 2175-2182, 2008.

[136] A. O. Aliprantis, Y. Ueki, R. Sulyanto et al., "NFATc1 in mice represses osteoprotegerin during osteoclastogenesis and dissociates systemic osteopenia from inflammation in cherubism," The Journal of Clinical Investigation, vol. 118, no. 11, pp. 3775-3789, 2008.

[137] K. Kim, J. H. Kim, J. Lee et al., "Nuclear factor of activated T cells $\mathrm{cl}$ induces osteoclast-associated receptor gene expression during tumor necrosis factor-related activation-induced cytokine-mediated osteoclastogenesis," The Journal of Biological Chemistry, vol. 280, no. 42, pp. 35209-35216, 2005.

[138] E. M. Grössinger, M. Kang, L. Bouchareychas et al., "Ca2 +-dependent regulation of NFATc1 via KCa3.1 in inflammatory osteoclastogenesis," The Journal of Immunology, vol. 200, no. 2, pp. 749-757, 2018.

[139] J. Y. Kim, J. Y. Min, J. M. Baek et al., "CTRP3 acts as a negative regulator of osteoclastogenesis through AMPK-c-FosNFATc1 signaling _in vitro_ and RANKL-induced calvarial bone destruction_in vivo_,”Bone, vol. 79, pp. 242-251, 2015.

[140] N. Yamaguchi, T. Kukita, Y. J. Li et al., “Adiponectin inhibits induction of TNF- $\alpha /$ RANKL-stimulated NFATc1 via the AMPK signaling," FEBS Letters, vol. 582, no. 3, pp. 451456, 2008.

[141] N. K. Shevde, A. C. Bendixen, K. M. Dienger, and J. W. Pike, "Estrogens suppress RANK ligand-induced osteoclast 
differentiation via a stromal cell independent mechanism involving c-Jun repression," Proceedings of the National Academy of Sciences of the United States of America, vol. 97, no. 14, pp. 7829-7834, 2000.

[142] S. Srivastava, G. Toraldo, M. N. Weitzmann, S. Cenci, F. P. Ross, and R. Pacifici, "Estrogen decreases osteoclast formation by down-regulating receptor activator of NF- $\kappa \mathrm{B}$ ligand (RANKL)-induced JNK activation," The Journal of Biological Chemistry, vol. 276, no. 12, pp. 8836-8840, 2001.

[143] V. García Palacios, L. J. Robinson, C. W. Borysenko, T. Lehmann, S. E. Kalla, and H. C. Blair, "Negative regulation of RANKL-induced osteoclastic differentiation in RAW264.7 cells by estrogen and phytoestrogens," The Journal of Biological Chemistry, vol. 280, no. 14, pp. 13720-13727, 2005. 